Research Article

\title{
Comparative Study on the Test Method for Tensile Elastic Modulus of Rock Materials
}

\author{
Yan Zhang $\mathbb{D I}^{1}$ and Dawei Y $\mathbf{u}^{2}$ \\ ${ }^{1}$ School of Safety Science and Emergency Management, Wuhan University of Technology, Wuhan 430070, China \\ ${ }^{2}$ Department of Civil Engineering, China University of Geosciences (Beijing), Beijing 100083, China
}

Correspondence should be addressed to Yan Zhang; zhangyanwatering@whut.edu.cn

Received 20 March 2019; Revised 21 May 2019; Accepted 13 June 2019; Published 1 July 2019

Academic Editor: Robert Černý

Copyright (c) 2019 Yan Zhang and Dawei Yu. This is an open access article distributed under the Creative Commons Attribution License, which permits unrestricted use, distribution, and reproduction in any medium, provided the original work is properly cited.

\begin{abstract}
Rock material has different mechanical behaviors under compressive and tensile loading. Correspondingly, there are two types of elastic modulus: compressive elastic modulus $E_{\mathrm{c}}$ and tensile elastic modulus $E_{\mathrm{t}}$, respectively. To distinguish which indirect test methodology, including three-points bending test and Brazilian disc test, is more suitable to measure the tensile elastic modulus $E_{\mathrm{t}}$ of rock materials, a series of uniaxial compressive test (UCT), direct tensile test (DTT), three-points bending test, and Brazilian disc test are performed for three typical types of rock: marble, granite, and sandstone. Comparative investigation on the reliability of measurement results of tensile elastic modulus $E_{\mathrm{t}}$ is systematically conducted. Finally, it is found that Brazilian disc test could be a suitable method to measure tensile elastic modulus of rock materials, due to the excellent agreement with that measured by DTT and the simplicity of sample preparation, as well as test operation.
\end{abstract}

\section{Introduction}

Elastic modulus of rock materials is an inherent parameter, describing the deformation characteristics of rock material under loading. It plays an important role regardless of quantitative numerical modelling, or in the qualitative evaluation system of engineering rock mass. It has been well known that rock material has different mechanical behaviors under compressive and tensile loading [1, 2]. Consequently, elastic modulus of rock material is classified into compressive elastic modulus and tensile elastic modulus. Generally, rock material has much more excellent performance under compression than that under tension. Therefore, it is a design goal to let the vast majority of rock material to be in the compression state in rock engineering. However, there still is tensile stress inevitably appearing at some special parts in the engineering practice, for example, the back edge area of a large-scale slope as illustrated in Figure 1(a) and the surrounding rock of a large-scale underground cavern in the zone with high geostress $[3,4]$ as illustrated in Figure 1(b).
In previous investigation, little attention was specially paid on the tensile deformation and induced tensile failures in rock materials. The behavior of rock materials was treated as the same under compression and tension states. As a result, the deformation of rock in tensile zones is significantly underestimated. It could bring great risk to the safe service of engineering infrastructures. Until recent years, the mechanism of tensile deformation and induced tensile failures increasingly attract more and more attention from scientists and engineers in the field of rock engineering $[5,6]$. As an important inherent parameter estimating the tensile deformation, it is meaningful to develop test methods to reliably measure the tensile elastic modulus of rock materials. In the estimation of deformation in rock engineering, compressive elastic modulus and tensile elastic modulus of rock should both be used.

For the measurement of tensile elastic modulus $E_{\mathrm{t}}$ of rock materials, there generally are three kinds of test methods: (1) direct tensile test (DTT), (2) three-point bending test, and (3) Brazilian disc test. The DTT method is a kind of direct method, while three-point bending test and 


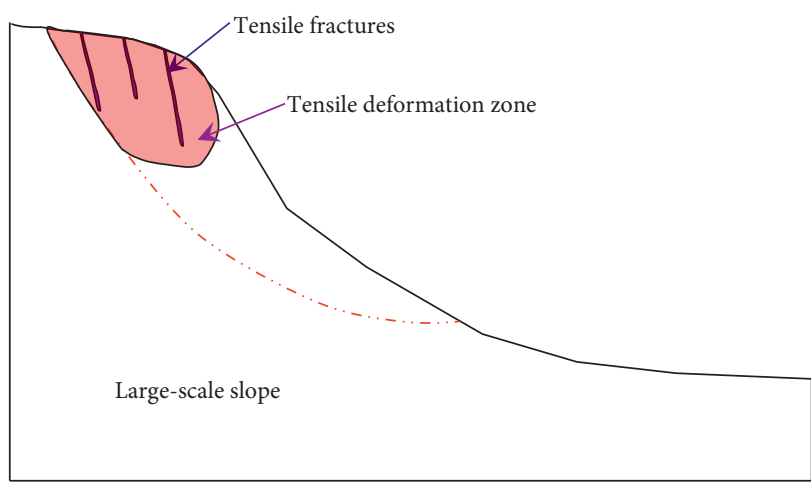

(a)

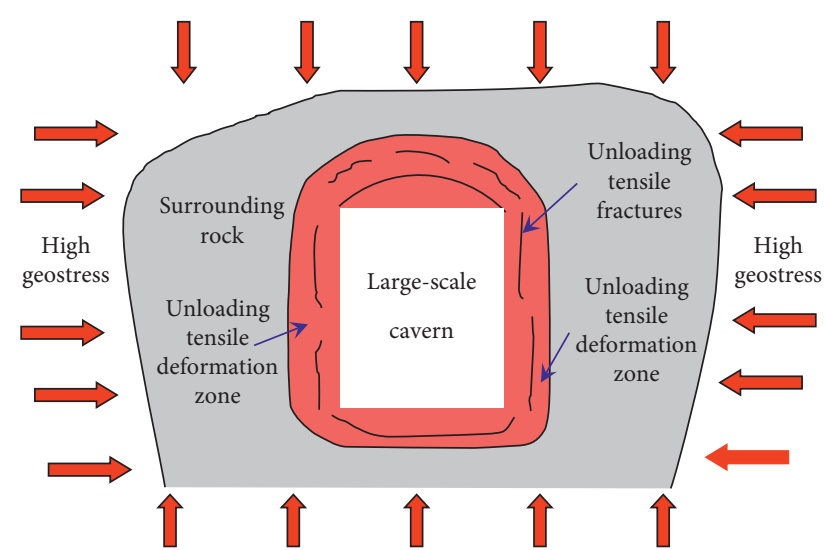

(b)

FIGURE 1: Typical rock engineering where tensile stress appears in special zones. (a) Large-scale slope. (b) Large-scale underground cavern with high geostress.

Brazilian disc test are two indirect methods. Undoubtedly, DTT method is the best method to measure $E_{t}$. However, its success rate is very low due to the complexity of sample preparation and testing operation. Generally, indirect methods are popular for measuring the tensile elastic parameters of rock materials due to the fact that relatively high success rate could be guaranteed. Three-point bending test was initially used to only measure the tensile strength of rock material. It was further improved to estimate the tensile elastic modulus by sticking strain gauges on the sample of rock beam [7]. However, three-point bending test also has the shortage that the preparation of the sample of rock beam is relatively complex. Brazilian disc test would be the most popular test method for the measurement of the tensile strength of rock materials $[8,9]$. There were also several test methods proposed to measure the elastic modulus of rock by Brazilian disc test, for example, Hondros [10], Yu and Wang et al. [11] and Wang et al. [12]. However, the elastic modulus of compression and tension is not distinguished in the above test methods. In 2009, Ye et al. [13] proposed a theory perfect test method to estimate the tensile elastic modulus of rock materials adopting Brazilian disc test. This test method has attracted much attention not only from the field of rock engineering [14, 15], but also from the field of material science, such as composite materials [16-18] and ceramics [19]. After that, Ye et al. [20] further improved the method to measure the tensile and compressive elastic modulus of rock materials synchronously by adopting the digital image correction (DIC) technique. The usage of DIC technique to observe the deformation of the disc in Brazilian disc test becomes more and more popular thereafter [21-24]. Until recently, Patel and Martin [25] further demonstrates the feasibility of DIC technique for the measurement of tensile elastic modulus of rock materials adopting Brazilian disc test. However, due to the fact that the measurement accuracy of strain of DIC technique is difficult to reach the order of $\mathrm{O}$ $\left(10^{-6}\right)$, the method proposed by Ye et al. [20] is not suitable for hard brittle rock.

Although there have been two kinds of indirect test methods for the tensile elastic modulus of rock materials, to the authors' knowledge so far, there still is no systematic comparative investigation for the three-point bending test and Brazilian disc test on the tensile elastic modulus measurement. Namely, there is no investigation so far to ask the following questions: (1) which test method gives out the measurement results more close to that measured by DTT and (2) which test method is more worth to be suggested to measure the tensile elastic modulus of rock materials, in terms of simplicity of testing operation and reliability of measured results.

In this study, taking three typical types of rock (marble, granite, and sandstone) as the representatives, a series of uniaxial compressive test (UCT), DTT, three-point bending test, and Brazilian disc test are performed. Comparative investigation on the reliability of measurement results is systematically conducted to ask the above mentioned two questions. Finally, it is found that Brazilian disc test could be a suitable method to measure the tensile elastic modulus of rock materials, due to the excellent agreement with that measured by DTT and the simplicity of sample preparation, as well as test operation.

\section{Experimental Methods}

2.1. Uniaxial Compressive Test (UCT). Uniaxial compressive test (UCT) is a kind of simple and conventional test in rock mechanics. Traditionally, only one set of stain gauge is glued on the lateral side of rock sample to record the axial and radial deformation. However, four sets of strain rosettes are glued symmetrically on the lateral side of samples in this study, as illustrated in Figure 2, to record more deformation information due to the possible inhomogeneity. As a result, four sets of curves of stress-axial strain, as well as stressradial strain, can be obtained for each sample. For each set of curve of stress-strain, the compressive elastic modulus $E_{\mathrm{c}}$ of the rock sample is determined as the slope of stress-axial strain curve; Poisson's ratio is the ratio of radial strain to axial strain where the stress is half of its peak value. Finally, four compressive elastic modulus $E_{\mathrm{c}}$ and four Poisson's ratio $v$ can be measured in only one test procedure for each rock 


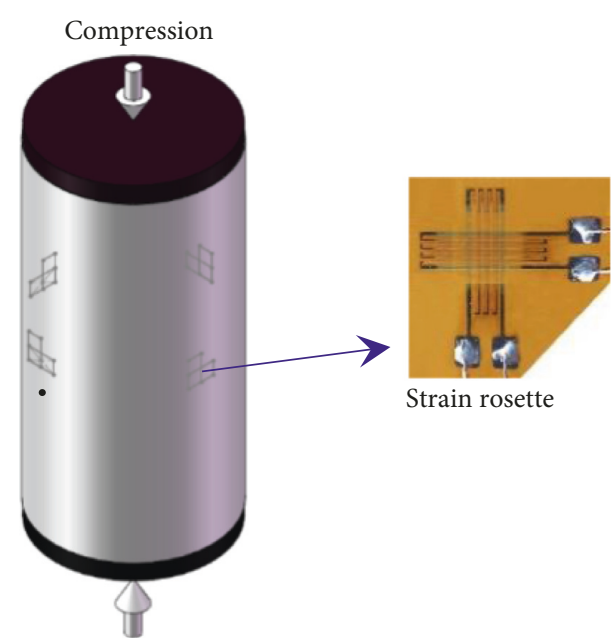

Figure 2: Sketch of the sample for uniaxial compression test. Four strain rosettes are glued on the lateral side of samples to record the axial and radical deformation.

sample. In this study, UCT are conducted by the way of displacement controlling. The loading rate applied by test apparatus is set as $0.15 \mathrm{~mm} / \mathrm{min}$.

2.2. Direct Tensile Test (DTT). Direct tensile test (DTT) is an unconventional test in rock mechanics due to the fact that it is apparently difficult to apply tensile load on rock samples. In the previous testing, the rock samples were generally made as the shape of dog bone with loading hole at ends. This sample preparation procedure was very cumbersome. Consequently, direct tensile test generally was not conducted. Alternatively, the Brazilian disc test was widely used to measure the tensile strength of rock materials proposed by ISRM [9] and ASTM [26]. Recently, in the past ten years, a kind of cementing material called epoxy adhesive tube kit $2216 \mathrm{~B} / \mathrm{A}$ with high bonding strength for rock is used in the direct tensile test. As a result, rock sample nowadays can be cylindrical, rather than dog bone shape. The cementing glue sticks the rock sample and two tensile loading heads together, as illustrated in Figure 3. Before starting the direct tensile test, the cementing glue sticking rock sample and loading heads must be placed for 24 hours, making sure the sticking strength between rock sample and loading heads is higher than that of rock sample. Furthermore, it must be guaranteed that the axes of rock sample and tensile loading heads coincide, avoiding the failure resulting from the existence of eccentricity.

Like that in the uniaxial compressive test, four sets of strain rosettes are glued symmetrically on the lateral side of the samples in the direct tensile test, to record four sets of axial tensile strain and radial strain. Also, the tensile elastic modulus $E_{\mathrm{t}}$ of rock sample is directly determined as the slope of tensile stress-axial strain curve; Poisson's ratio in tensile status is the ratio of radial strain to axial strain where the tensile stress is half of its peak value. In this study, the loading rate in the direct tensile test is set as $0.15 \mathrm{~mm} / \mathrm{min}$.

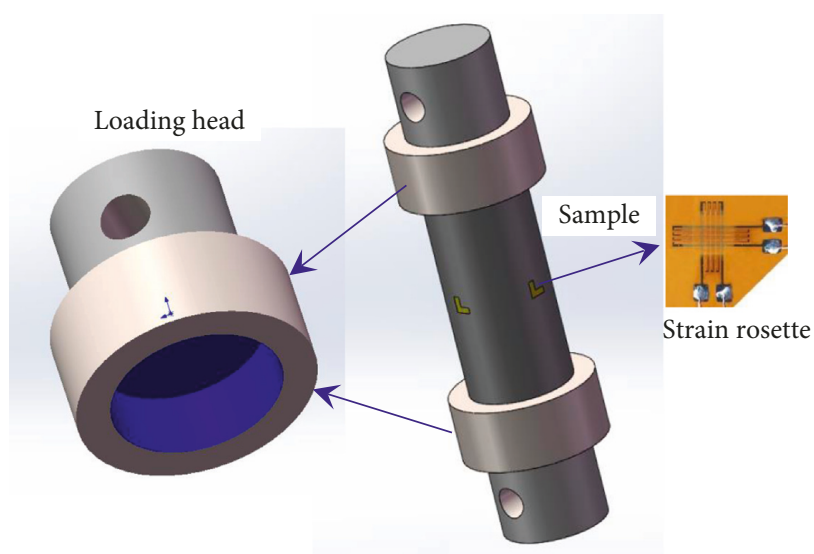

FIGURE 3: Sketch of the samples for direct tension test. Four strain rosettes are glued on the lateral side of samples.

2.3. Three-Point Bending Test. The three-point bending test is also a kind of alternate test method to measure the tensile strength of rock materials. Some improvements have been made attempting to synchronously measure the compressive elastic modulus and tensile elastic modulus adopting threepoint bending test [7] because the upper part of beam sample is in compressive state; meanwhile, the lower part is in the tensile state, as illustrated in Figure 4 . An obvious priority for measuring $E_{\mathrm{c}}$ and $E_{\mathrm{t}}$ of rock materials at the same time is that the stress status in the beam sample is very simple, and its analytical solution is available for this three-point bending test. For the sake of clarity, the basic theory to measure $E_{\mathrm{c}}$ and $E_{\mathrm{t}}$ of rock materials is briefly summarized as following.

As illustrated in Figure 4, a beam with height $h$ and thickness $b$ is applied by a force $P$ on the symmetrical plane. Two fulcrums with a distance $L$ support the beam at the bottom. Taking the symmetrical plane as the focus, the stress on it in $x$ direction must be in equilibrium firstly:

$$
\frac{1}{2} \sigma_{\mathrm{c}} b h_{1}=\frac{1}{2} \sigma_{\mathrm{t}} b h_{2}
$$

where $\sigma_{\mathrm{c}}$ and $\sigma_{\mathrm{t}}$ are the maximum compressive stress at upper boundary and the maximum tensile stress at the bottom of beam. Secondly, the moment around $z$ axis also must be in equilibrium:

$$
\frac{1}{4} \mathrm{PL}=\frac{1}{3} \sigma_{\mathrm{c}} b h_{1}^{2}+\frac{1}{3} \sigma_{\mathrm{t}} b h_{2}^{2},
$$

where $h_{1}$ and $h_{2}\left(h=h_{1}+h_{2}\right)$ are the height of compressive and tensile zones, respectively. Finally, the deformation coordination relation on the symmetrical plane satisfies [7]

$$
\frac{h_{1}}{h_{2}}=\frac{\varepsilon_{\mathrm{c}}}{\varepsilon_{\mathrm{t}}},
$$

where $\varepsilon_{\mathrm{c}}$ and $\varepsilon_{\mathrm{t}}$ are the maximum compressive strain at upper boundary and the maximum tensile strain at the bottom of beam. At elastic deformation stage of rock material, applying Hooke's law $\sigma_{\mathrm{c}}=E_{\mathrm{c}} \varepsilon_{\mathrm{c}}, \sigma_{\mathrm{t}}=E_{\mathrm{t}} \varepsilon_{\mathrm{t}}$, the following formulation is established: 


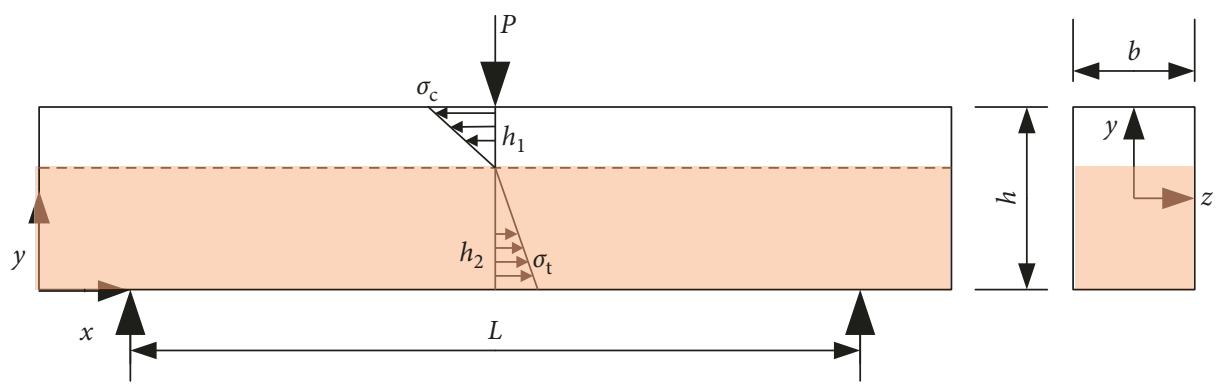

FIGURE 4: Diagram of compressive and tensile stress in three-points bending test.

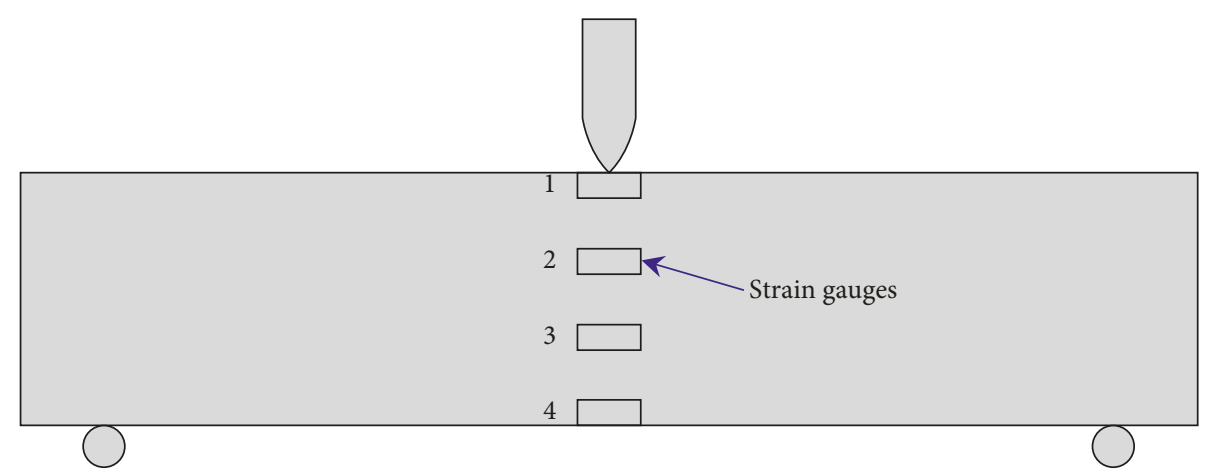

(a)

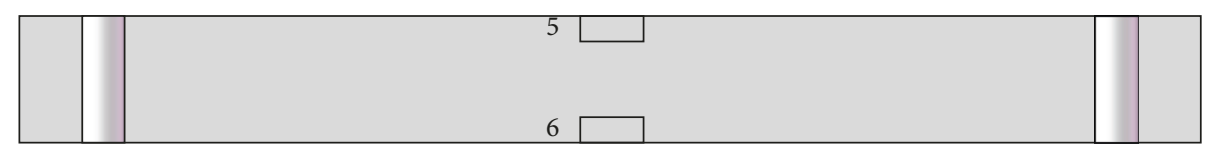

(b)

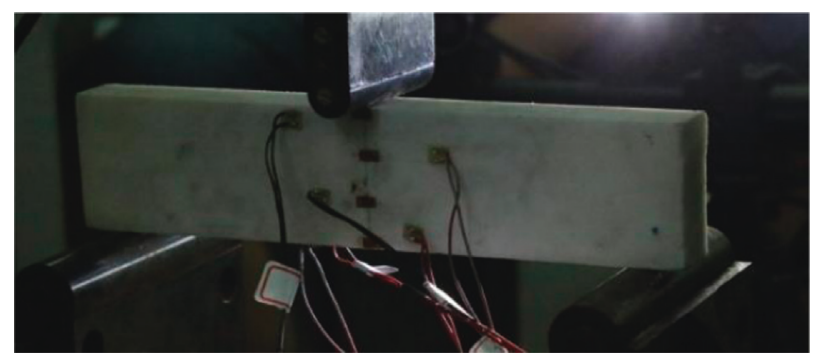

(c)

FiguRE 5: Sketch of the rock sample of three-point bending test. Four strain gauges are glued on the front lateral side and two are glued on the bottom of sample beam. (a) Front view. (b) Bottom view. (c) A real view.

$$
\begin{aligned}
& E_{\mathrm{c}}=\frac{3 \mathrm{PL}}{4 h^{2} b}\left(1+\frac{\varepsilon_{\mathrm{t}}}{\varepsilon_{\mathrm{c}}}\right) \frac{1}{\varepsilon_{\mathrm{c}}}, \\
& E_{\mathrm{t}}=\frac{3 \mathrm{PL}}{4 h^{2} b}\left(1+\frac{\varepsilon_{\mathrm{t}}}{\varepsilon_{\mathrm{c}}}\right) \frac{\varepsilon_{c}}{\varepsilon_{\mathrm{t}}^{2}} .
\end{aligned}
$$

Based on equations (4) and (5), it is expected to measure the compressive elastic modulus $E_{c}$ and tensile elastic modulus $E_{\mathrm{t}}$ of rock materials, so long as the applied loading $P$, and maximum compressive strain $\varepsilon_{\mathrm{c}}$ at upper boundary and the maximum tensile strain $\varepsilon_{\mathrm{t}}$ at the bottom of beam are recorded in elastic deformation stage.
In this study, totally six strain gauges are glued on the beam sample to record the deformation. Among them, four are glued on the front lateral side (Nos. 1 to 4), and two (Nos. 5 and 6) are on the bottom of beam, as illustrated in Figure 5. Strain gauge No. 1 can record the maximum compressive strain $\varepsilon_{\mathrm{c}}$ at the upper boundary; strain gauge Nos. 4,5 , and 6 record the maximum tensile strain $\varepsilon_{\mathrm{t}}$ at the bottom. The applied loading $P$ is recorded by a force sensor in testing.

2.4. Brazilian Disc Test. Brazilian disc test is a kind of popular test method to measure the tensile strength of materials in the field of rock mechanics proposed by ISRM [9] and ASTM [26]. Its advantages include the following: (1) 


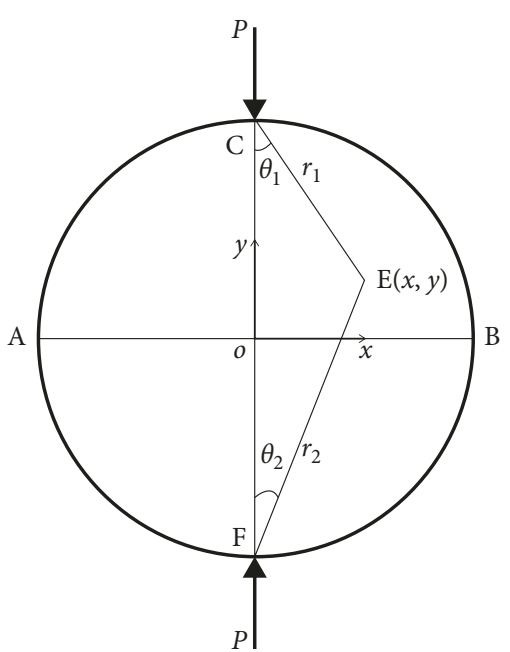

(a)

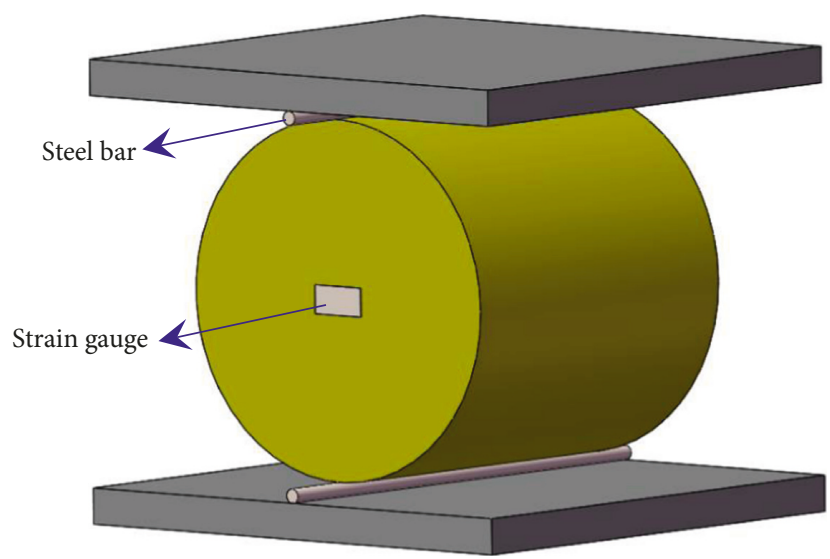

(b)

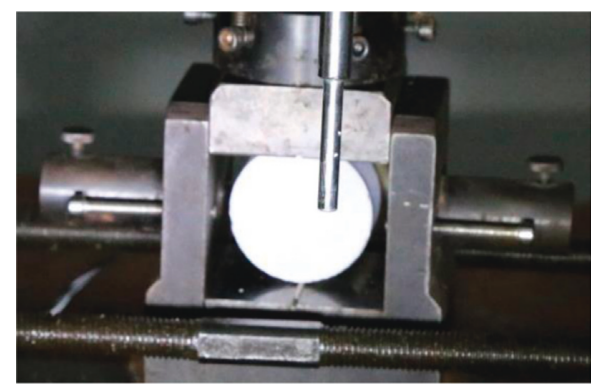

(c)

FIgURE 6: Sketch of the Brazilian disc test. A strain gauge is horizontally glued at the center on the front lateral side of disc to record the tensile deformation. (a) Diagram for analytical solution. (b) Sketch of the test. (c) A real view.

sample preparation is easy; (2) testing procedure and operation is relatively simple; and (3) the closed form analytical solution of stress in disc is available, making the testing theory rigorous. Ye et al. [13] gave out the analytical solution of stress in disc applied by two concentrated point loading (Figure 6(a)) as

$$
\begin{aligned}
& \sigma_{x}=\frac{2 P}{\pi l}\left\{\frac{(D / 2-y) x^{2}}{\left((D / 2-y)^{2}+x^{2}\right)^{2}}+\frac{(D / 2+y) x^{2}}{\left((D / 2+y)^{2}+x^{2}\right)^{2}}-\frac{1}{D}\right\}, \\
& \sigma_{y}=\frac{2 P}{\pi l}\left\{\frac{(D / 2-y)^{3}}{\left((D / 2-y)^{2}+x^{2}\right)^{2}}+\frac{(D / 2+y)^{3}}{\left((D / 2+y)^{2}+x^{2}\right)^{2}}-\frac{1}{D}\right\}, \\
& \tau_{x y}=\frac{2 P}{\pi l}\left\{\frac{(D / 2-y)^{2} x}{\left((D / 2-y)^{2}+x^{2}\right)^{2}}-\frac{(D / 2+y)^{2} x}{\left((D / 2+y)^{2}+x^{2}\right)^{2}}\right\},
\end{aligned}
$$

where $D$ is the diameter of disc, $P$ is the applied force, and $l$ is the thickness of disc. Based the above analytical solution of disc, Ye et al. [13] further proposed a theoretic formulation to measure the tensile elastic modulus $E_{\mathrm{t}}$ of rock materials (Figure 6(b)):

$$
\begin{aligned}
E_{\mathrm{t}}(t) & =\frac{2 P(t)}{\pi D \varepsilon_{\mathrm{t}}(t)}\left\{\left(1-\frac{D}{L} \arctan \frac{2 L}{D}\right)(1-\nu)+\frac{2 D^{2}(1+\nu)}{4 L^{2}+D^{2}}\right\} \\
& =A \times E_{\mathrm{s}},
\end{aligned}
$$

in which

$$
\begin{aligned}
& E_{\mathrm{S}}=\frac{2 P}{\pi D \varepsilon_{\mathrm{t}}}, \\
& A=\left(1-\frac{D}{L} \arctan \frac{2 L}{D}\right)(1-\nu)+\frac{2 D^{2}(1+\nu)}{4 L^{2}+D^{2}} .
\end{aligned}
$$

$\varepsilon_{t}$ is the strain recorded by the gauge horizontally glued at the center of disc. $E_{\mathrm{s}}$ is named as splitting elastic modulus in Ye et al. [13]. $A$ is a correction coefficient related to the size of disc and strain gauge, as well as Poisson's ratio $v$. It must be determined under the state of compression. This is the reason why the uniaxial compression test needs to be conducted in this study. $t$ in equation (7) represents time. It means that tensile elastic modulus $E_{\mathrm{t}}$ of rock materials could be variable with time. In the real test procedure (Figure 6(c)), once the applied force $P$ and strain $\varepsilon_{\mathrm{t}}$ are recorded synchronously, the tensile elastic modulus $E_{\mathrm{t}}$ of rock materials could be measured adopting equations (7)-(9). 


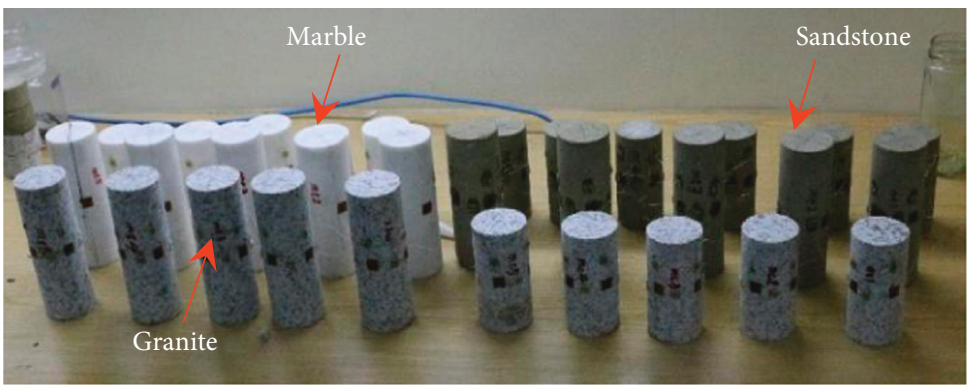

(a)
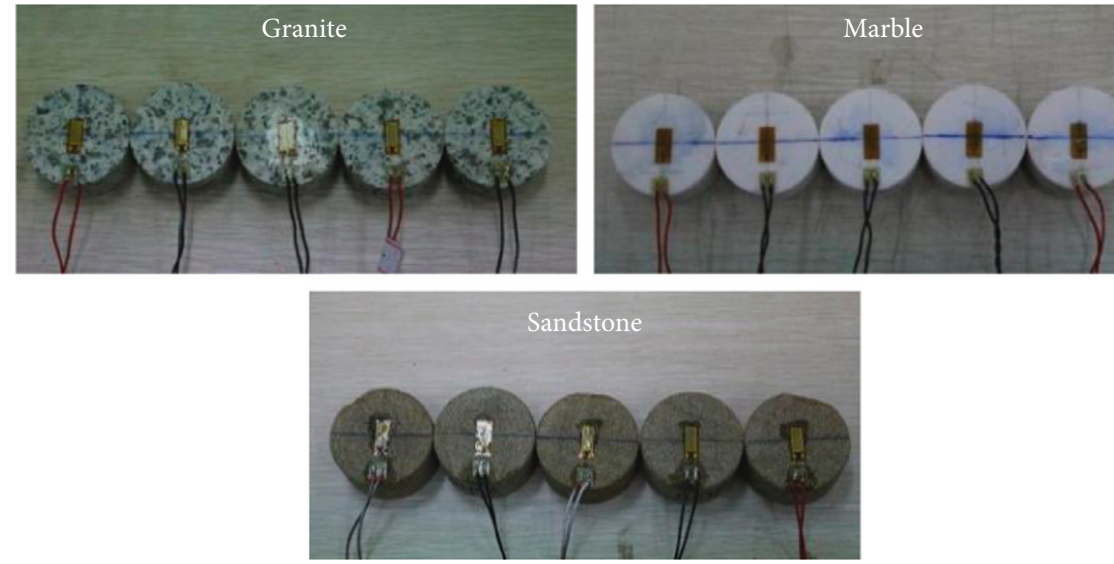

(b)
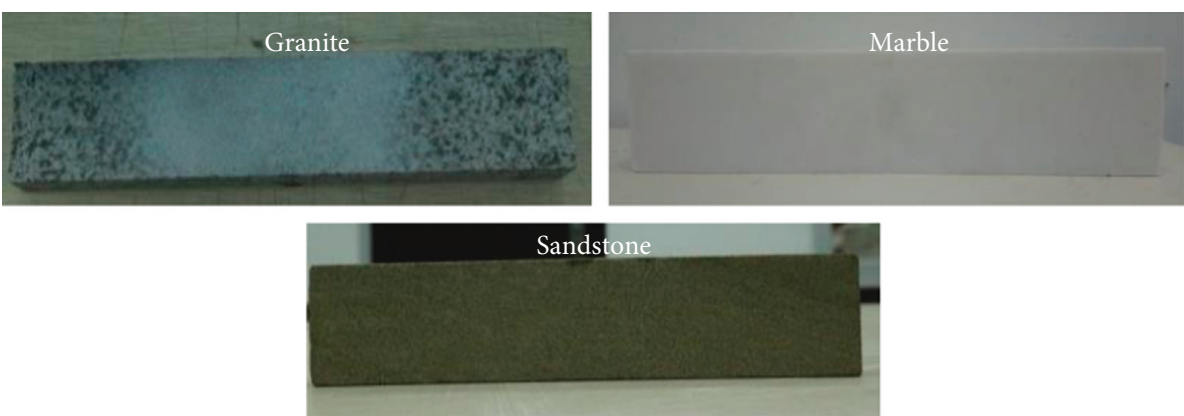

(c)

FIgURE 7: A view of rock samples for (a) UCT and DTT, (b) Brazilian disc test, and (c) three-point bending test.

\section{Experimental Results}

3.1. Test Samples. In this study, three types of typical rock are selected as the representatives. They are granite, white marble, and sandstone. All test samples are prepared according to related Chinese specifications [27] or international standards $[9,26,28,29]$ in the field of rock mechanics. In order to guarantee the reliability of test results, five sets of parallel testing are conducted for each type of test and each type of rock. Totally 60 rock samples are prepared (Figure 7). The size of all rock samples is listed in Tables 1 and 2. Numbering the rock samples follows the following rules. (1) The first character represents the rock type: " $M$ " is marble, " $G$ " is granite, and " $S$ " is sandstone. (2) The second character represents the test type: " $\mathrm{C}$ " is the compression test, " $\mathrm{T}$ " is the tension test, " $W$ " is the three-point bending test, and " $P$ " is the
Brazilian disc test. (3) The third represents the sequence in the five parallel testing.

3.2. UCT and DTT Results. A real view of the unaxial compressive test (UCT) and direct tensile test (DTT) for rock samples is shown in Figures 8 and 9, respectively. The typical failure model of rock samples in UCT and DTT is shown in Figures 10 and 11, respectively. Following, the detailed test results of marble, granite, and sandstone are analyzed one by one.

3.2.1. Marble's Results. The typical stress-strain curves obtained from UCT and DTT for marble are shown in Figure 12. In previous study, generally only one set of strain gauge is glued on the lateral side of samples. Here, four sets of 
TABLE 1: Size of rock samples for UCT and DTT.

\begin{tabular}{|c|c|c|c|c|c|c|c|}
\hline Rock & Serial number & $D(\mathrm{~mm})$ & $H(\mathrm{~mm})$ & Serial number & $D(\mathrm{~mm})$ & $H(\mathrm{~mm})$ & $\rho\left(\mathrm{g} / \mathrm{cm}^{3}\right)$ \\
\hline \multirow{5}{*}{ Marble } & MC1 & 49.76 & 100.23 & MT1 & 50.21 & 139.82 & \multirow{5}{*}{2.72} \\
\hline & MC2 & 49.8 & 100.31 & MT2 & 50.23 & 139.8 & \\
\hline & MC3 & 49.86 & 100.25 & MT3 & 50.28 & 139.78 & \\
\hline & MC4 & 49.75 & 100.21 & MT4 & 50.24 & 139.84 & \\
\hline & MC5 & 49.83 & 100.19 & MT5 & 50.2 & 139.76 & \\
\hline \multirow{5}{*}{ Granite } & GC1 & 50.21 & 100.03 & GT1 & 49.82 & 138.95 & \multirow{5}{*}{2.45} \\
\hline & GC2 & 50.16 & 100.11 & GT2 & 49.76 & 139.81 & \\
\hline & GC3 & 50.32 & 100.25 & GT3 & 49.85 & 138.93 & \\
\hline & GC4 & 50.12 & 100.11 & GT4 & 49.73 & 139.81 & \\
\hline & GC5 & 50.22 & 100.14 & GT5 & 49.89 & 139.65 & \\
\hline \multirow{5}{*}{ Sandstone } & SC1 & 50.11 & 99.73 & ST1 & 49.86 & 139.25 & \multirow{5}{*}{2.14} \\
\hline & SC2 & 50.36 & 99.86 & ST2 & 49.86 & 138.91 & \\
\hline & SC3 & 50.25 & 99.83 & ST3 & 49.75 & 139.21 & \\
\hline & SC4 & 50.23 & 99.69 & ST4 & 49.74 & 138.84 & \\
\hline & SC5 & 50.21 & 99.78 & ST5 & 49.92 & 138.65 & \\
\hline
\end{tabular}

TABLE 2: Size of rock samples for the three-point bending test and Brazilian disc test.

\begin{tabular}{|c|c|c|c|c|c|c|}
\hline Rock & Serial number & $L \times H \times B(\mathrm{~mm})$ & Serial number & $D(\mathrm{~mm})$ & $l(\mathrm{~mm})$ & $\rho\left(\mathrm{g} / \mathrm{cm}^{3}\right)$ \\
\hline \multirow{5}{*}{ Marble } & MW1 & $278.21 \times 60.34 \times 30.12$ & MP1 & 49.82 & 25.21 & \multirow{5}{*}{2.72} \\
\hline & MW2 & $278.43 \times 60.24 \times 30.23$ & MP2 & 49.8 & 24.87 & \\
\hline & MW3 & $278.54 \times 60.31 \times 30.21$ & MP3 & 49.87 & 25.13 & \\
\hline & MW4 & $278.26 \times 60.25 \times 30.15$ & MP4 & 49.82 & 25.25 & \\
\hline & MW5 & $278.36 \times 60.23 \times 30.16$ & MP5 & 49.85 & 25.13 & \\
\hline \multirow{5}{*}{ Granite } & GW1 & $279.51 \times 60.24 \times 30.21$ & GP1 & 49.73 & 25.32 & \multirow{5}{*}{2.45} \\
\hline & GW2 & $278.83 \times 60.22 \times 30.33$ & GP2 & 49.72 & 24.75 & \\
\hline & GW3 & $278.84 \times 60.12 \times 30.18$ & GP3 & 49.76 & 25.26 & \\
\hline & GW4 & $278.56 \times 60.30 \times 30.16$ & GP4 & 49.86 & 25.21 & \\
\hline & GW5 & $279.16 \times 60.13 \times 30.26$ & GP5 & 49.81 & 25.32 & \\
\hline \multirow{5}{*}{ Sandstone } & SW1 & $279.51 \times 60.34 \times 30.27$ & SP1 & 49.75 & 25.22 & \multirow{5}{*}{2.14} \\
\hline & SW2 & $278.83 \times 60.14 \times 30.12$ & SP2 & 49.74 & 24.85 & \\
\hline & SW3 & $278.84 \times 60.23 \times 30.31$ & SP3 & 49.8 & 24.83 & \\
\hline & SW4 & $278.56 \times 60.19 \times 30.23$ & SP4 & 49.76 & 24.76 & \\
\hline & SW5 & $279.16 \times 60.31 \times 30.06$ & SP5 & 49.71 & 24.86 & \\
\hline
\end{tabular}

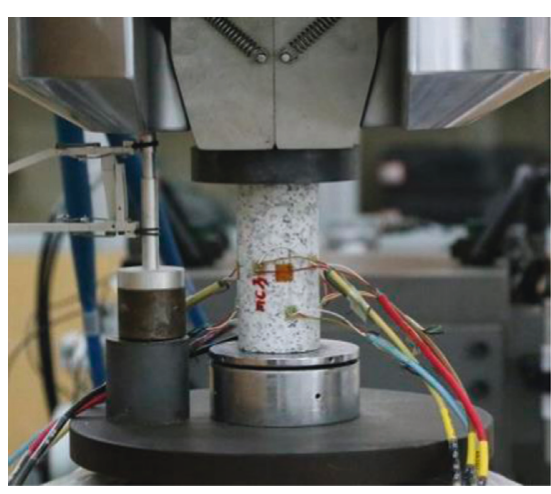

(a)

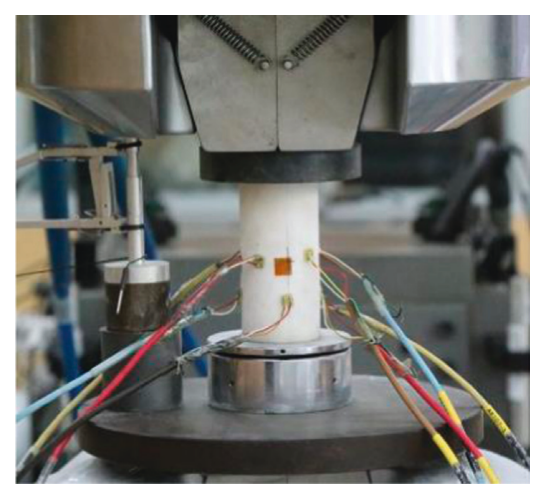

(b)

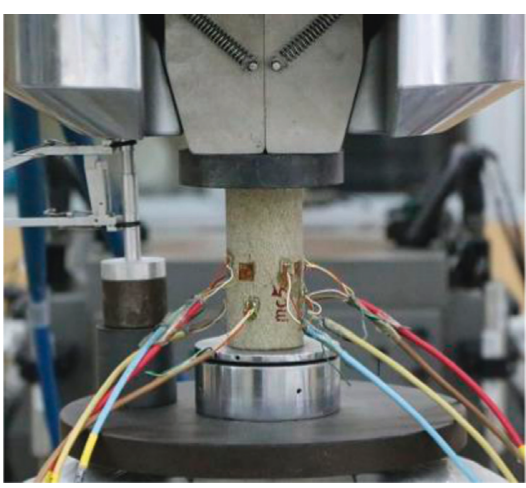

(c)

Figure 8: A real view of UCT. (a) Granite. (b) Marble. (c) Sandstone.

stress-strain are obtained because four sets of strain gauges are used in tests. As illustrated in Figure 12, the recorded strain by different strain gauge is not the same, indicating that the deformation is not homogeneous in the whole rock sample. Due to the existence of various errors resulting from, for example, test apparatus itself, sensors, artificial operation, and 


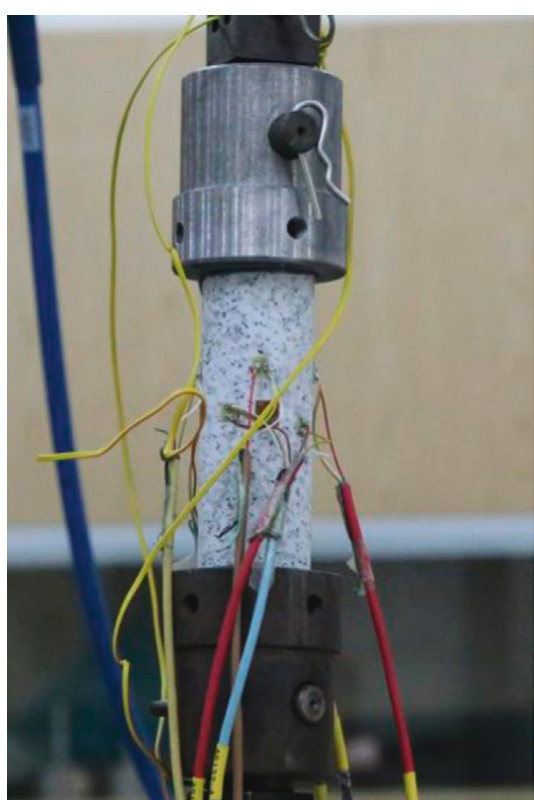

(a)

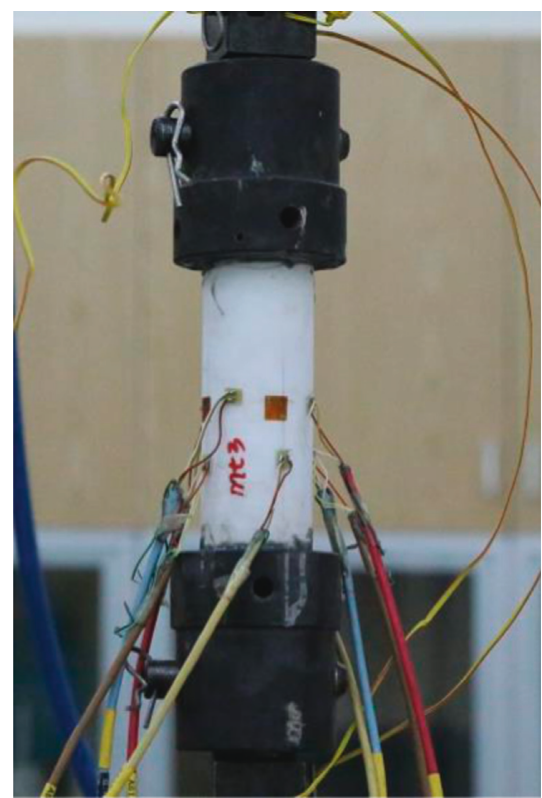

(b)

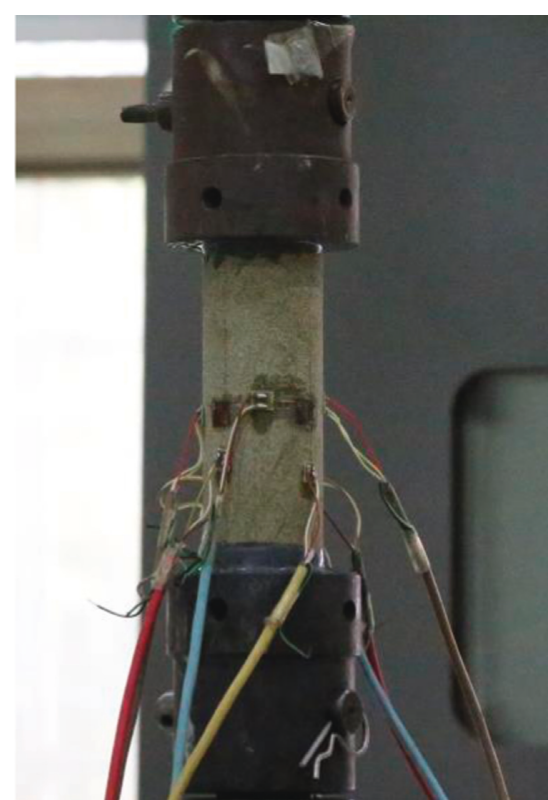

(c)

Figure 9: A real view of DTT. (a) Granite. (b) Marble. (c) Sandstone.

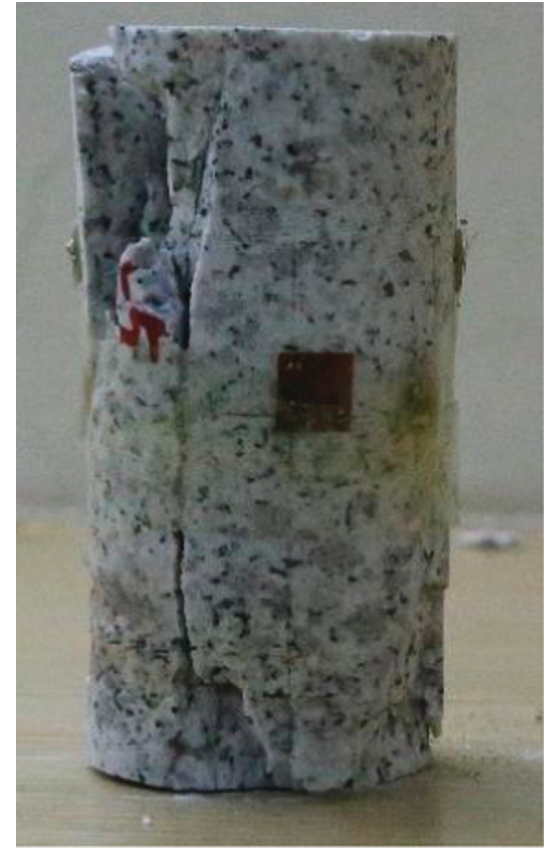

(a)

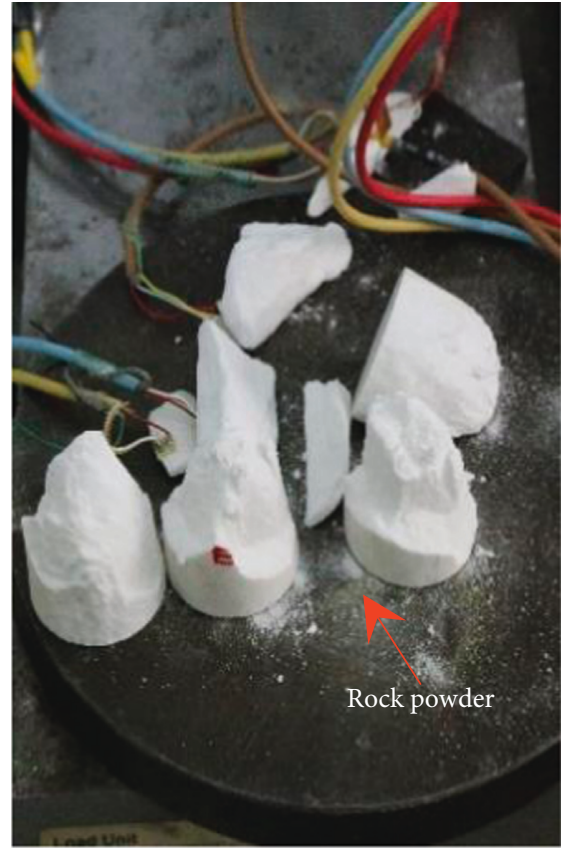

(b)

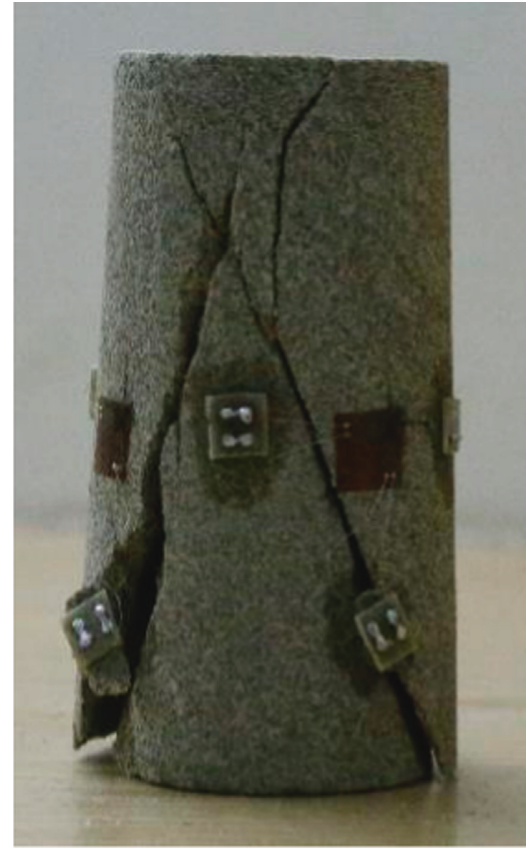

(c)

Figure 10: Typical failure model of rock samples after UCT. (a) Granite. (b) Marble. (c) Sandstone.

some other unknown random factors, some strain measurement could be not reasonable, for example, the strain recorded by gauge 8 shown in Figure 12(a). Therefore, results of deformation measurement could be not representative or accurate if only one strain gauge is used.

According to the testing method presented in Sections 2.1 and 2.2, the compressive elastic modulus $E_{c}$, tensile elastic modulus $E_{t}$, and Poisson's ratio $v$ of marble are determined. All results are listed in Table 3. In case a recorded strain is obviously not reasonable, it will not be used when processing data. “-” is placed at the related position in Table 3.

As shown in Table 3, the compressive strength of marble used in this study is huge, reaching up to $126.2 \mathrm{MPa}$, averaging 107.6 MPa. However, its tensile strength from DTT is apparently small, being only $0.7-1.4 \mathrm{MPa}$. This huge 


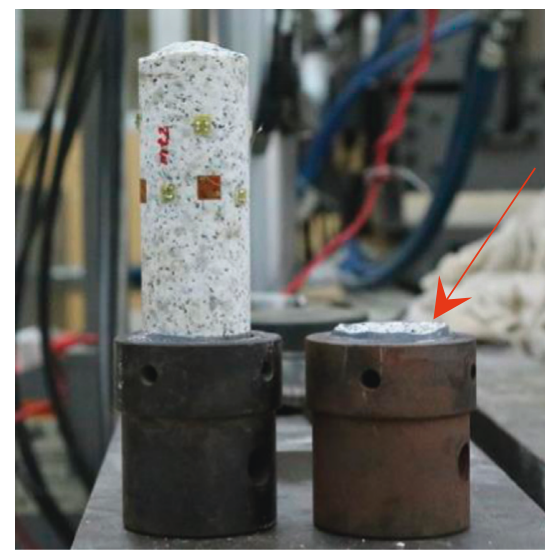

(a)

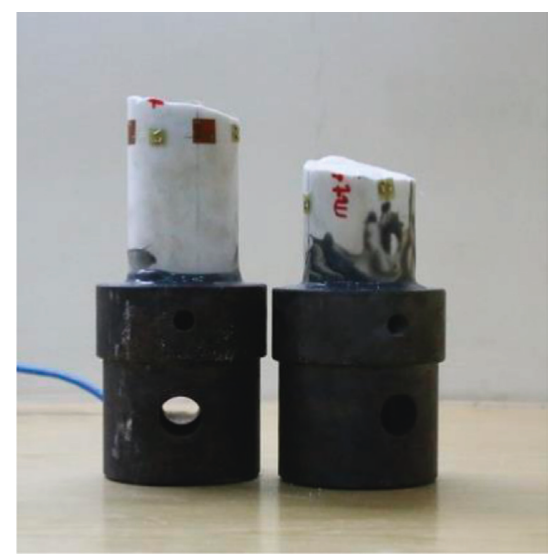

(b)

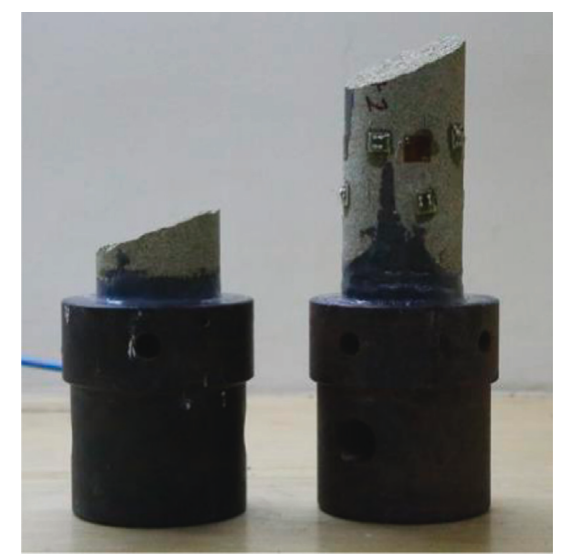

(c)

Figure 11: Typical failure model of rock samples after DTT. (a) Granite. (b) Marble. (c) Sandstone.
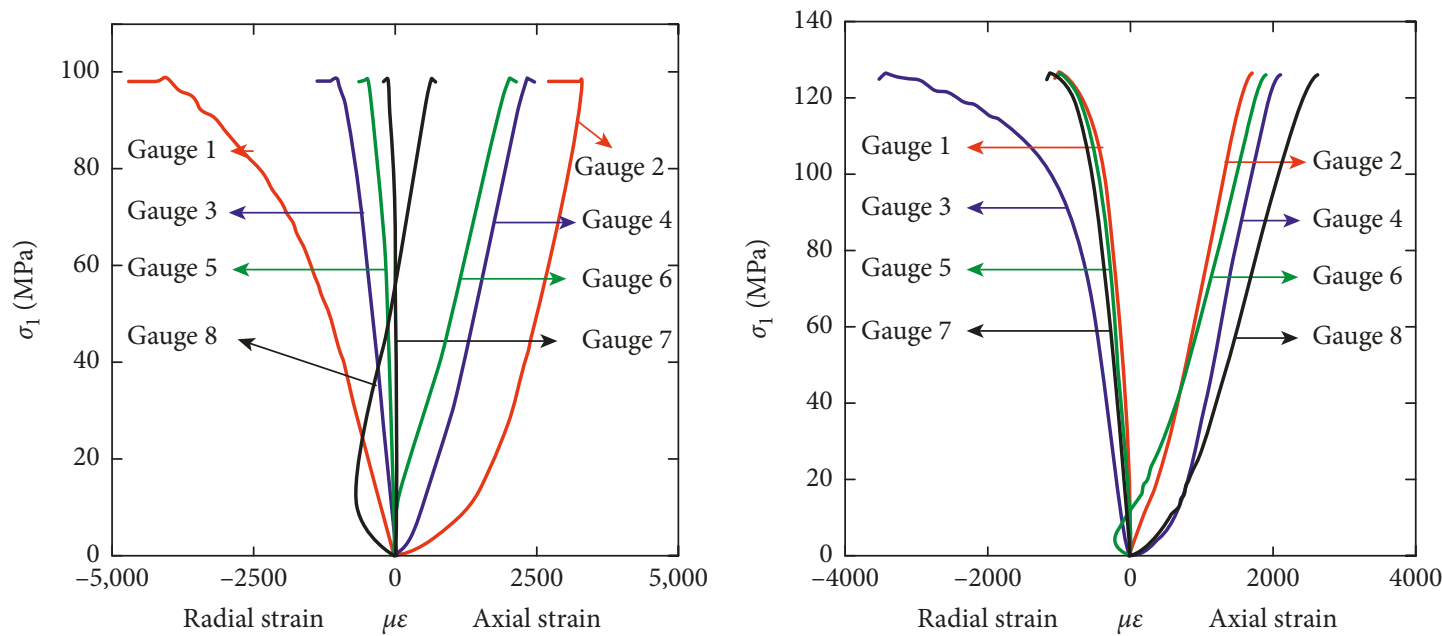

(a)

(b)

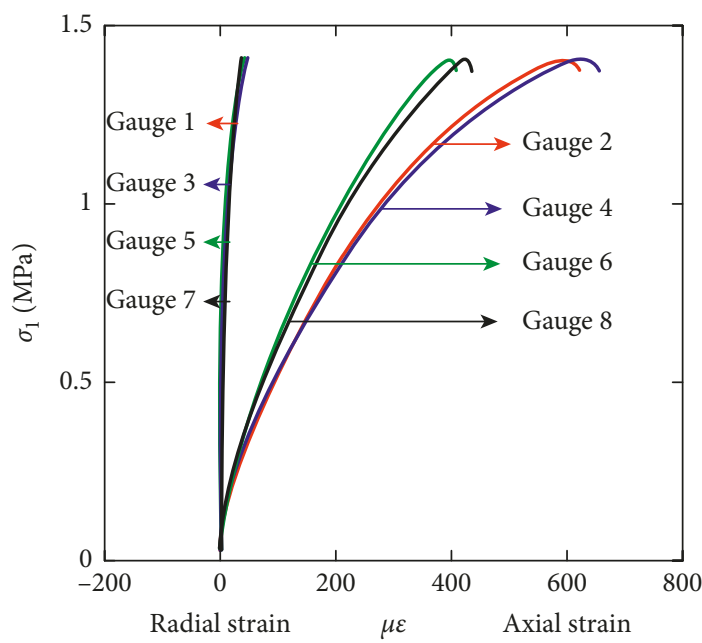

(c)

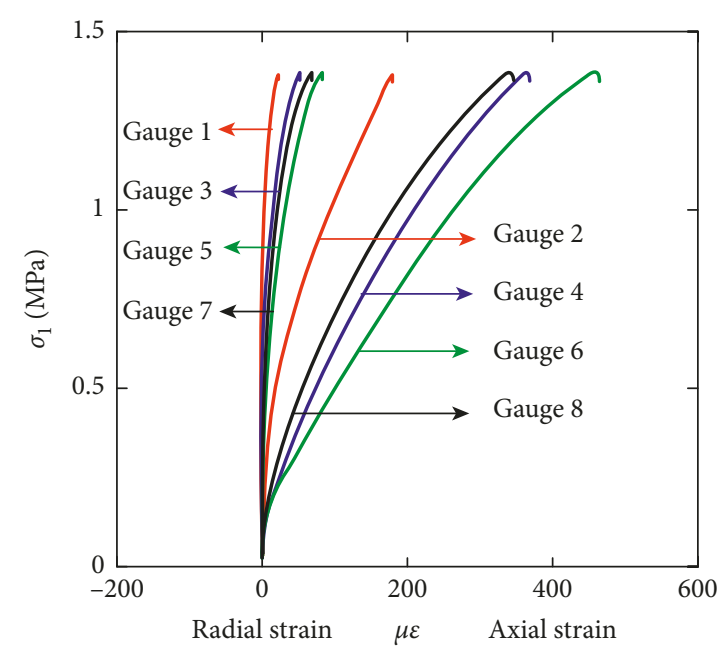

(d)

FIgURE 12: Typical stress-strain curves obtained from UCT and DTT for marble $\left(1 \mu \varepsilon=1.0 \times 10^{-6}\right)$. (a) MC2. (b) MC4. (c) MT2. (d) MT3. 
TABLE 3: Test results of UCT and DTT for marble.

\begin{tabular}{|c|c|c|c|c|c|c|c|c|c|}
\hline $\mathrm{SN}$ & Gauge number & $E_{\mathrm{c}}(\mathrm{GPa})$ & $\mu$ & $\sigma_{\mathrm{c}}(\mathrm{MPa})$ & $\mathrm{SN}$ & Gauge number & $E_{\mathrm{t}}(\mathrm{GPa})$ & $\mu$ & $\sigma_{\mathrm{t}}(\mathrm{MPa})$ \\
\hline \multirow{5}{*}{$\mathrm{MC1}$} & 1,2 & - & 0.24 & \multirow{5}{*}{123.7} & \multirow{5}{*}{ MT1 } & 1,2 & 2.0 & - & \multirow{5}{*}{1.4} \\
\hline & 3,4 & - & 0.18 & & & 3,4 & - & - & \\
\hline & 5,6 & 69.8 & 0.38 & & & 5,6 & 4.7 & 0.11 & \\
\hline & 7,8 & 62.2 & 0.32 & & & 7,8 & 2.0 & - & \\
\hline & Mean & 66.0 & 0.28 & & & Mean & 2.2 & 0.11 & \\
\hline \multirow{5}{*}{ MC2 } & 1,2 & 50.7 & - & \multirow{5}{*}{98.8} & \multirow{5}{*}{ MT2 } & 1,2 & 2.9 & - & \multirow{5}{*}{1.4} \\
\hline & 3,4 & 55.2 & 0.27 & & & 3,4 & 2.6 & - & \\
\hline & 5,6 & 49.2 & - & & & 5,6 & 3.8 & - & \\
\hline & 7,8 & - & - & & & 7,8 & 3.6 & - & \\
\hline & Mean & 51.7 & 0.27 & & & Mean & 3.2 & - & \\
\hline \multirow{5}{*}{ MC4 } & 1,2 & - & 0.16 & \multirow{5}{*}{126.2} & \multirow{5}{*}{ MT3 } & 1,2 & 6.6 & 0.05 & \multirow{5}{*}{1.4} \\
\hline & 3,4 & - & 0.38 & & & 3,4 & 3.7 & - & \\
\hline & 5,6 & 65.7 & 0.21 & & & 5,6 & 3.1 & - & \\
\hline & 7,8 & 65.7 & 0.19 & & & 7,8 & 3.9 & - & \\
\hline & Mean & 65.7 & 0.23 & & & Mean & 4.3 & 0.05 & \\
\hline \multirow{10}{*}{ MC5 } & 1,2 & 81.2 & - & \multirow{5}{*}{81.8} & \multirow{5}{*}{ MT4 } & 1,2 & 5.1 & - & \multirow{5}{*}{0.7} \\
\hline & 3,4 & 61.2 & 0.35 & & & 3,4 & 2.4 & - & \\
\hline & 5,6 & - & - & & & 5,6 & 9.4 & - & \\
\hline & 7,8 & - & 0.27 & & & 7,8 & 3.7 & - & \\
\hline & Mean & 71.2 & 0.31 & & & Mean & 3.7 & - & \\
\hline & & & & & \multirow{5}{*}{ MT5 } & 1,2 & 2.3 & - & \multirow{5}{*}{1.4} \\
\hline & & & & & & 3,4 & 4.8 & - & \\
\hline & & & & & & 5,6 & - & 0.15 & \\
\hline & & & & & & 7,8 & 3.5 & - & \\
\hline & & & & & & Mean & 2.7 & - & \\
\hline & tal mean & 63.6 & 0.27 & 107.6 & & Total mean & 3.7 & 0.1 & 1.3 \\
\hline
\end{tabular}

Note. The test for MC3 is not successful.

difference between compressive and tensile behavior can be attributed to the microstructure of this kind of marble. As shown in Figures 10(b) and 11(b), the rock blocks cannot get together, and some rock powder is generated after compression failure. SEM scanning (not shown here) indicates that the cemented minerals between particles make the marble own excellent compression capability, but weak tensile capacity.

It is observed in Figure 11 that the samples of marble and sandstone are pulled off at the middle part of samples, indicating that the DTT for marble and sandstone in this study is successful. However, the granite sample fails at the end. In this case, the measurement of tensile strength is not effective. However, the tensile elastic modulus $E_{\mathrm{t}}$ can still be effectively determined because there still is an elastic deformation stage before failure occurrence, regardless of breaking at the middle part or at end of rock samples. In this study, $60 \%$ of the direct tensile test (DTT) is successful; only a few samples break at end. From Table 3, it is known that the average of compressive elastic modulus $E_{\mathrm{c}}$ is $63.6 \mathrm{GPa}$, while that of the tensile elastic modulus $E_{\mathrm{t}}$ is $3.7 \mathrm{GPa}$.

3.2.2. Granite's Results. The typical stress-strain curves obtained from UCT and DTT for granite are shown in Figure 13. It is also shown that the strain is different recorded in one sample test. Taking the same data processing method with marble, the compressive elastic modulus $E_{\mathrm{c}}$, tensile elastic modulus $E_{\mathrm{t}}$, and Poisson's ratio $v$ of granite are determined and listed in Table 4.
It is known from Table 4 that the compressive strength of the granite is also relatively high, ranging from $61.5 \mathrm{MPa}$ to 85.9 $\mathrm{MPa}$, averaging 74.7 $\mathrm{MPa}$, while its tensile strength is only 2.2 MPa to 4.0 MPa. The difference is considerable. The compressive elastic modulus of granite ranges from $23.1 \mathrm{GPa}$ to $63.4 \mathrm{GPa}$, averaging $37.3 \mathrm{GPa}$. The tensile elastic modulus ranges from $9.1 \mathrm{GPa}$ to $23.6 \mathrm{GPa}$, averaging $14.8 \mathrm{GPa}$.

3.2.3. Sandstone's Results. The typical stress-strain curves obtained from UCT and DTT for sandstone are shown in Figure 14. Taking the same data processing method with marble, the compressive elastic modulus $E_{c}$, tensile elastic modulus $E_{t}$, and Poisson's ratio $v$ of sandstone are determined and listed in Table 5.

It is known from Table 4 that the compressive strength of the sandstone is also relatively high, ranging from $20.5 \mathrm{MPa}$ to $24.7 \mathrm{MPa}$, averaging 22.4 MPa, while its tensile strength is only $0.27 \mathrm{MPa}$ to $0.99 \mathrm{MPa}$. The difference also is considerable. The compressive elastic modulus of sandstone ranges from $2.5 \mathrm{GPa}$ to $5.2 \mathrm{GPa}$, averaging $3.4 \mathrm{GPa}$. The tensile elastic modulus ranges from $1.8 \mathrm{GPa}$ to $4.3 \mathrm{GPa}$, averaging 3.0 GPa. Although the strength under compression and tension state is also significantly different for sandstone, the elastic modulus under compression and tension state basically is close. Overall, the tensile elastic modulus is still less than the compressive elastic modulus.

3.3. Three-Point Bending Test Results. Typical compressive and tensile stress-strain curves of marble, granite, and 


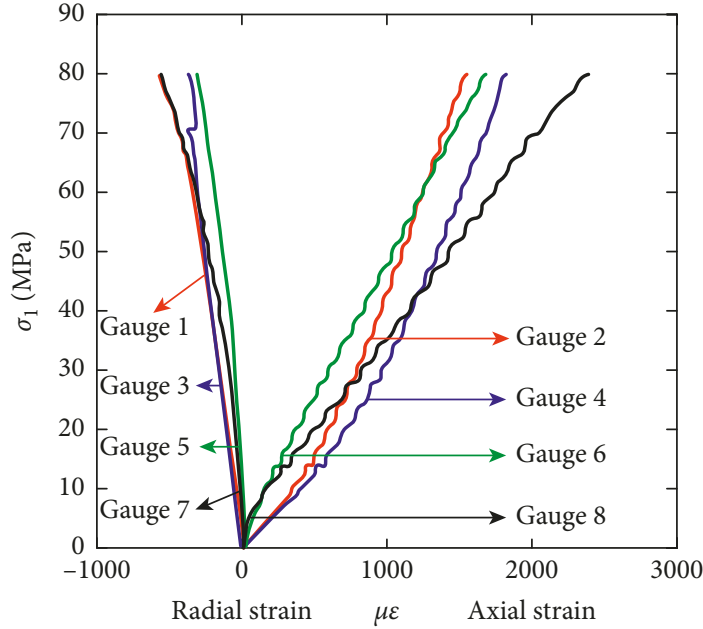

(a)

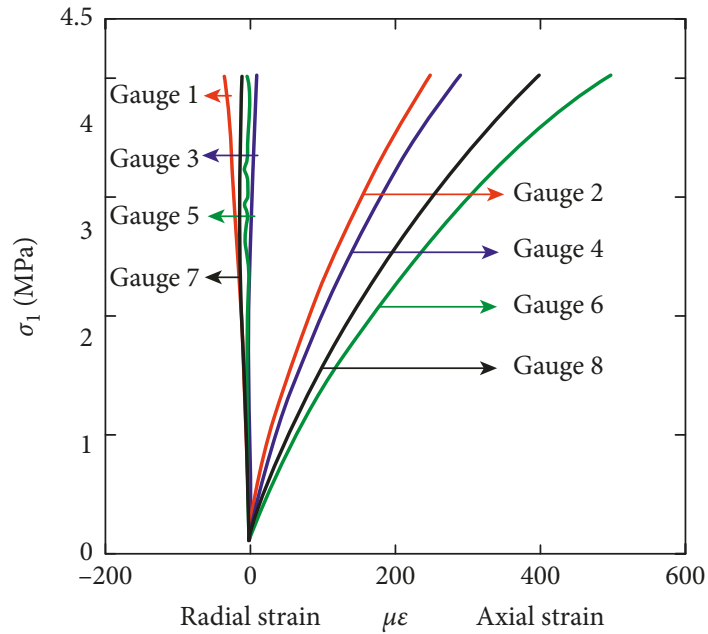

(c)

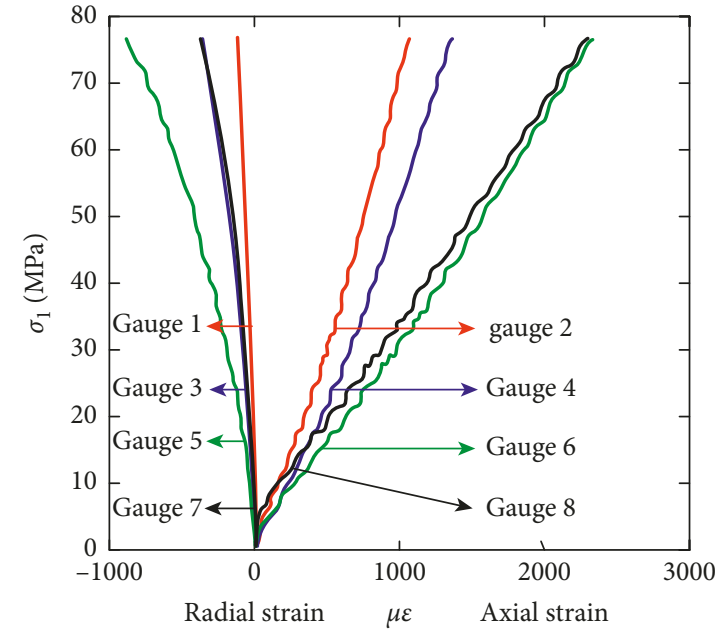

(b)

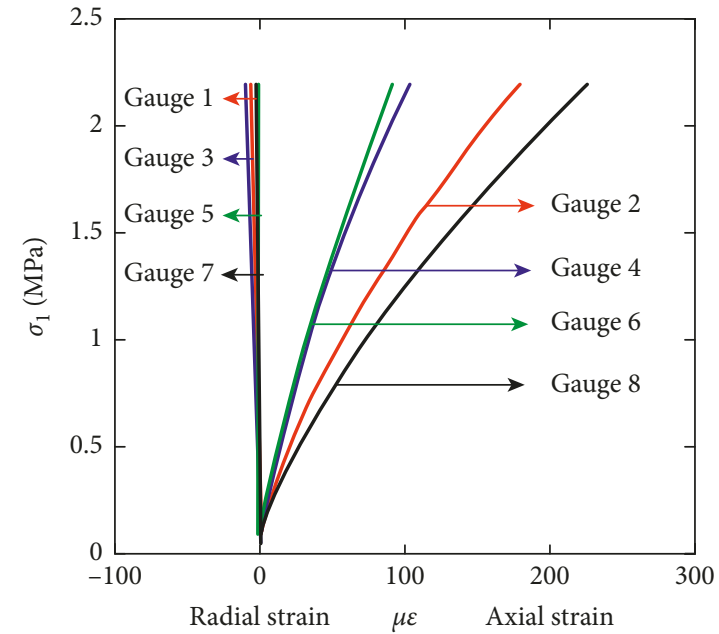

(d)

FIGURe 13: Typical stress-strain curves obtained from UCT and DTT for granite $\left(1 \mu \varepsilon=1.0 \times 10^{-6}\right)$. (a) GC2. (b) GC4. (c) GT1. (d) GT3.

TABLE 4: Test results of UCT and DTT for granite.

\begin{tabular}{|c|c|c|c|c|c|c|c|c|c|}
\hline SN & Gauge number & $E_{\mathrm{c}}(\mathrm{GPa})$ & $\mu$ & $\sigma_{\mathrm{c}}(\mathrm{MPa})$ & SN & Gauge number & $E_{\mathrm{t}}(\mathrm{GPa})$ & $\mu$ & $\sigma_{\mathrm{t}}(\mathrm{MPa})$ \\
\hline \multirow{5}{*}{ GC1 } & 1,2 & - & - & \multirow{5}{*}{70.6} & \multirow{5}{*}{ GT1 } & 1,2 & 16.2 & 0.15 & \multirow[t]{5}{*}{4.0} \\
\hline & 3,4 & 57.0 & 0.25 & & & 3,4 & 13.7 & - & \\
\hline & 5,6 & 39.1 & 0.13 & & & 5,6 & 8.5 & 0.02 & \\
\hline & 7,8 & 23.1 & 0.18 & & & 7,8 & 10.5 & 0.08 & \\
\hline & Mean & 39.7 & 0.19 & & & Mean & 12.2 & 0.08 & \\
\hline \multirow{5}{*}{ GC2 } & 1,2 & 63.4 & 0.23 & \multirow{5}{*}{85.9} & \multirow{5}{*}{ GT3 } & 1,2 & 11.9 & 0.06 & \multirow[t]{5}{*}{2.2} \\
\hline & 3,4 & 53.2 & 0.19 & & & 3,4 & 21.3 & 0.10 & \\
\hline & 5,6 & 45.2 & 0.11 & & & 5,6 & 22.2 & - & \\
\hline & 7,8 & 32.6 & 0.15 & & & 7,8 & 9.1 & 0.01 & \\
\hline & Mean & 48.6 & 0.17 & & & Mean & 16.1 & 0.04 & \\
\hline \multirow{5}{*}{ GC3 } & 1,2 & 24.2 & - & \multirow{5}{*}{61.5} & \multirow{5}{*}{ GT4 } & 1,2 & 10.1 & - & \multirow[t]{5}{*}{3.8} \\
\hline & 3,4 & 26.4 & - & & & 3,4 & 15.5 & 0.06 & \\
\hline & 5,6 & - & - & & & 5,6 & 15.7 & 0.02 & \\
\hline & 7,8 & - & - & & & 7,8 & 23.6 & - & \\
\hline & Mean & 25.3 & & & & Mean & 16.2 & 0.04 & \\
\hline
\end{tabular}


TABle 4: Continued.

\begin{tabular}{|c|c|c|c|c|c|c|c|c|c|}
\hline SN & Gauge number & $E_{\mathrm{c}}(\mathrm{GPa})$ & $\mu$ & $\sigma_{\mathrm{c}}(\mathrm{MPa})$ & SN & Gauge number & $E_{\mathrm{t}}(\mathrm{GPa})$ & $\mu$ & $\sigma_{\mathrm{t}}(\mathrm{MPa})$ \\
\hline \multirow{5}{*}{ GC4 } & 1,2 & - & - & \multirow{5}{*}{84.8} & & & & & \\
\hline & 3,4 & - & 0.16 & & & & & & \\
\hline & 5,6 & 36.3 & 0.24 & & & & & & \\
\hline & 7,8 & 34.4 & - & & & & & & \\
\hline & Mean & 35.4 & 0.20 & & & & & & \\
\hline \multirow{5}{*}{ GC5 } & 1,2 & 35.1 & 0.19 & \multirow{5}{*}{70.5} & & & & & \\
\hline & 3,4 & 55.5 & - & & & & & & \\
\hline & 5,6 & 26.3 & 0.21 & & & & & & \\
\hline & 7,8 & 33.9 & - & & & & & & \\
\hline & Mean & 37.7 & 0.20 & & & & & & \\
\hline & tal mean & 37.34 & 0.19 & 74.7 & & Total mean & 14.8 & 0.05 & 3.3 \\
\hline
\end{tabular}

Note. The test for GT2 and GT5 is not successful.

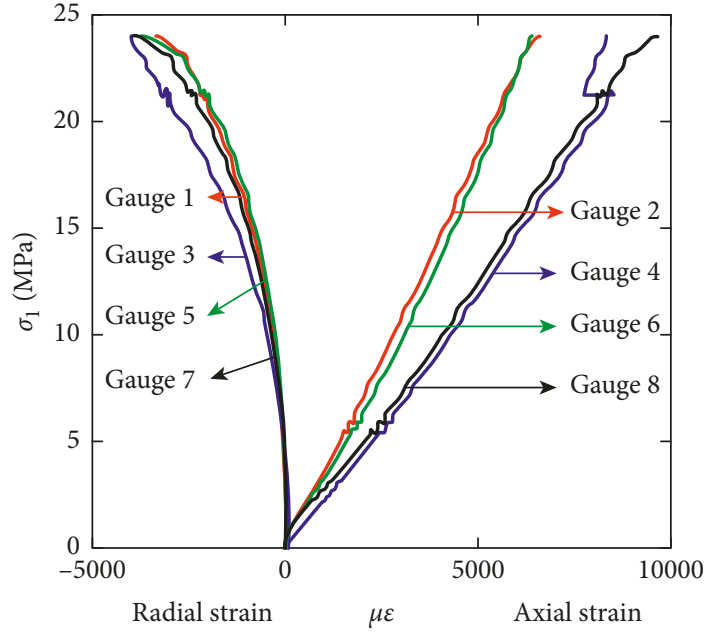

(a)

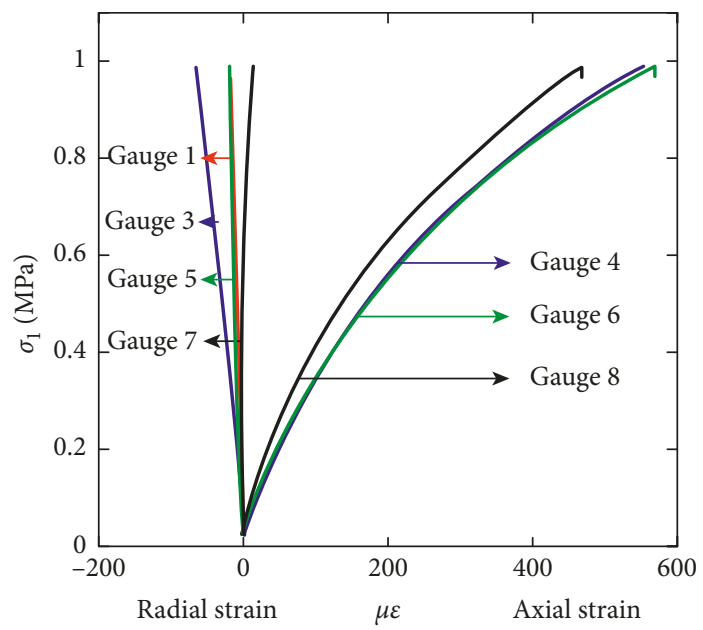

(c)

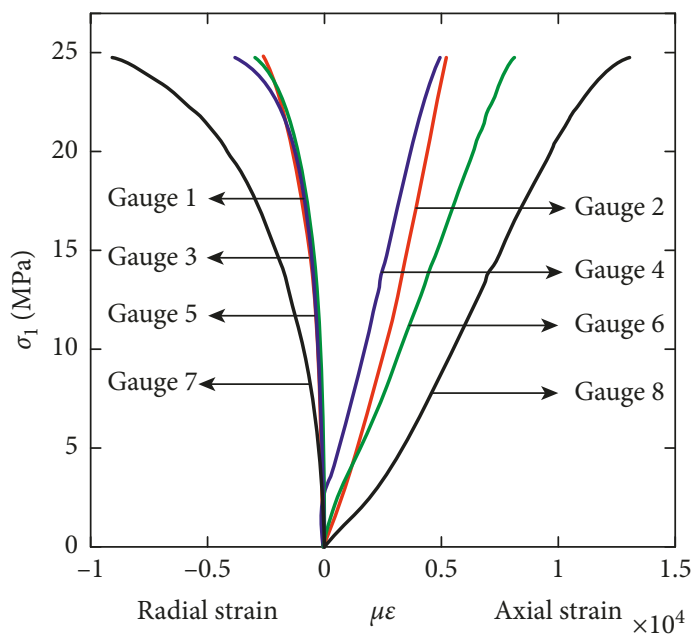

(b)

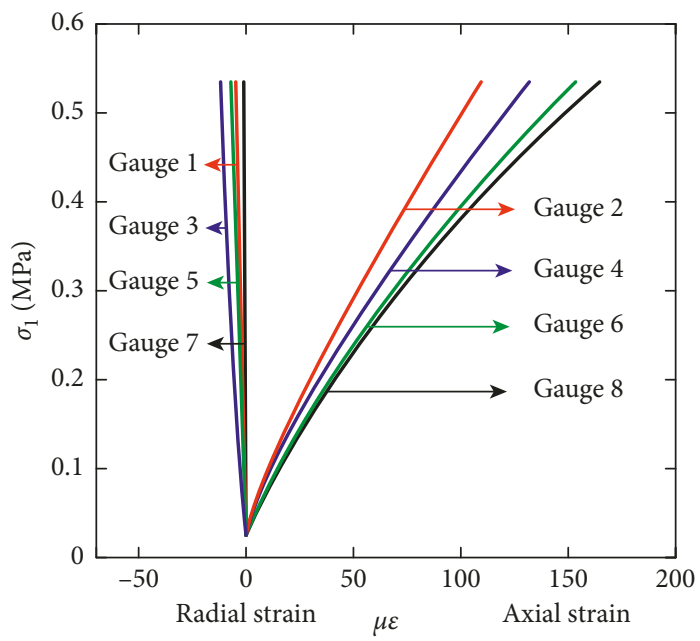

(d)

FIgURE 14: Typical stress-strain curves obtained from UCT and DTT for sandstone $\left(1 \mu \varepsilon=1.0 \times 10^{-6}\right)$. (a) SC1. (b) SC4. (c) ST3. (d) ST4.

sandstone obtained from the three-point bending test are shown in Figure 15. Due to the complexity of testing operation, and some other uncontrollable factors, the success rate of the three-point bending test is relatively low in this study. Even through 15 rock beam samples are prepared, only 6 tests are successful. Among them, marble has three successful tests, granite has two, and sandstone only has one. All results coming from successful tests are plotted in 
TABLE 5: Test results of UCT and DTT for sandstone.

\begin{tabular}{|c|c|c|c|c|c|c|c|c|c|}
\hline SN & Gauge number & $E_{\mathrm{c}}(\mathrm{GPa})$ & $\mu$ & $\sigma_{\mathrm{c}}(\mathrm{MPa})$ & $\mathrm{SN}$ & Gauge number & $E_{\mathrm{t}}(\mathrm{GPa})$ & $\mu$ & $\sigma_{\mathrm{t}}(\mathrm{MPa})$ \\
\hline \multirow{5}{*}{ SC1 } & 1,2 & 3.9 & 0.16 & \multirow{5}{*}{24.0} & \multirow{5}{*}{ ST2 } & 1,2 & 2.4 & 0.21 & \multirow{5}{*}{0.44} \\
\hline & 3,4 & 2.8 & 0.15 & & & 3,4 & 2.2 & 0.17 & \\
\hline & 5,6 & 4 & 0.12 & & & 5,6 & 3.6 & 0.30 & \\
\hline & 7,8 & 2.8 & 0.12 & & & 7,8 & - & - & \\
\hline & Mean & 3.4 & 0.14 & & & Mean & 2.8 & 0.23 & \\
\hline \multirow{5}{*}{ SC2 } & 1,2 & 4.7 & - & \multirow{5}{*}{20.5} & \multirow{5}{*}{ ST3 } & 1,2 & - & - & \multirow{5}{*}{0.99} \\
\hline & 3,4 & 5.2 & - & & & 3,4 & 1.9 & 0.17 & \\
\hline & 5,6 & 2.5 & - & & & 5,6 & 1.8 & 0.08 & \\
\hline & 7,8 & 2.9 & 0.23 & & & 7,8 & 2.3 & 0.00 & \\
\hline & Mean & 3.8 & 0.23 & & & Mean & 2.0 & 0.08 & \\
\hline \multirow{5}{*}{ SC4 } & 1,2 & 5.2 & 0.15 & \multirow{5}{*}{24.7} & \multirow{5}{*}{ ST4 } & 1,2 & 4.3 & 0.06 & \multirow{5}{*}{0.54} \\
\hline & 3,4 & 5 & 0.13 & & & 3,4 & 3.5 & 0.14 & \\
\hline & 5,6 & 3.2 & - & & & 5,6 & 3.1 & 0.06 & \\
\hline & 7,8 & 2.5 & 0.21 & & & 7,8 & 3.1 & - & \\
\hline & Mean & 4 & 0.16 & & & Mean & 3.5 & 0.09 & \\
\hline \multirow{5}{*}{ SC5 } & 1,2 & 3.9 & 0.09 & \multirow{5}{*}{21.4} & \multirow{5}{*}{ ST5 } & 1,2 & 3.8 & 0.21 & \multirow{5}{*}{0.27} \\
\hline & 3,4 & 3.2 & 0.12 & & & 3,4 & 3.8 & 0.30 & \\
\hline & 5,6 & 2.6 & 0.11 & & & 5,6 & 3.5 & 0.10 & \\
\hline & 7,8 & 2.9 & 0.09 & & & 7,8 & -- & 0.40 & \\
\hline & Mean & 3.2 & 0.10 & & & Mean & 3.7 & 0.25 & \\
\hline \multirow{5}{*}{ SC6 } & 1,2 & 2.6 & 0.10 & \multirow{5}{*}{21.6} & & & & & \\
\hline & 3,4 & 2.5 & 0.08 & & & & & & \\
\hline & 5,6 & 2.5 & 0.24 & & & & & & \\
\hline & 7,8 & 3 & 0.08 & & & & & & \\
\hline & Mean & 2.7 & 0.13 & & & & & & \\
\hline & Total mean & 3.4 & 0.15 & 22.4 & & Total mean & 3.0 & 0.16 & 0.56 \\
\hline
\end{tabular}

Note. The test for ST1 is not successful.

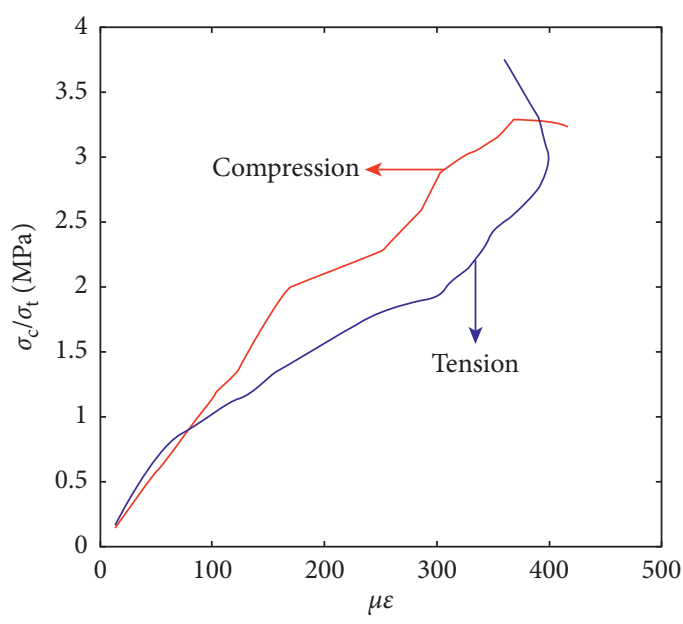

(a)

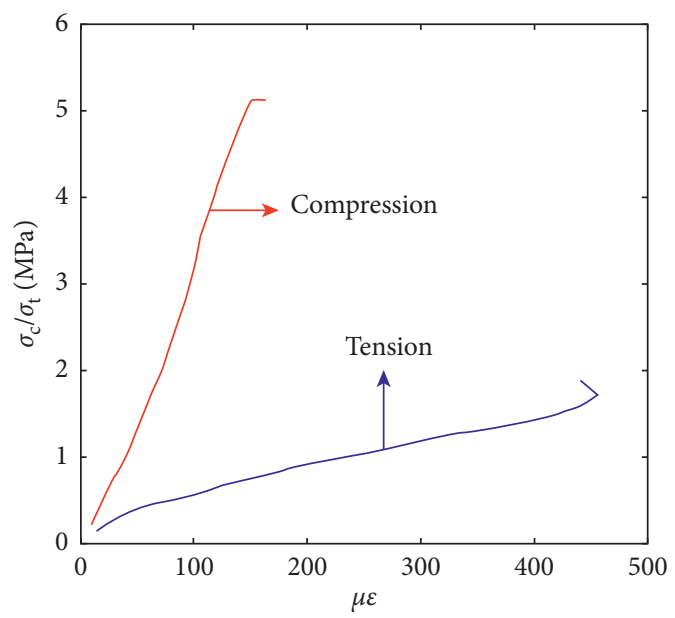

(b)

Figure 15: Continued. 


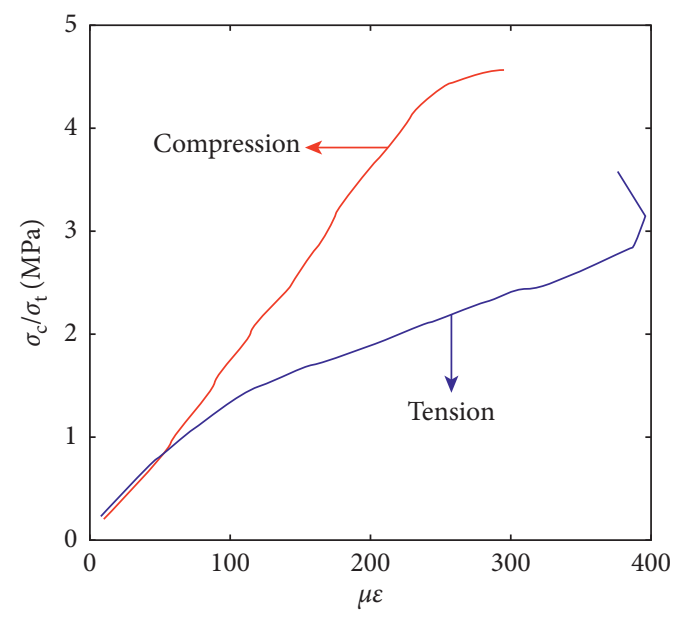

(c)

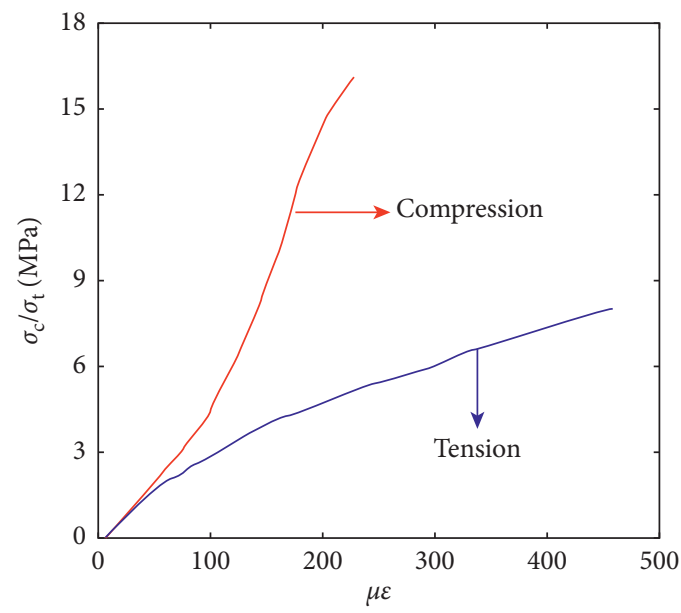

(e)

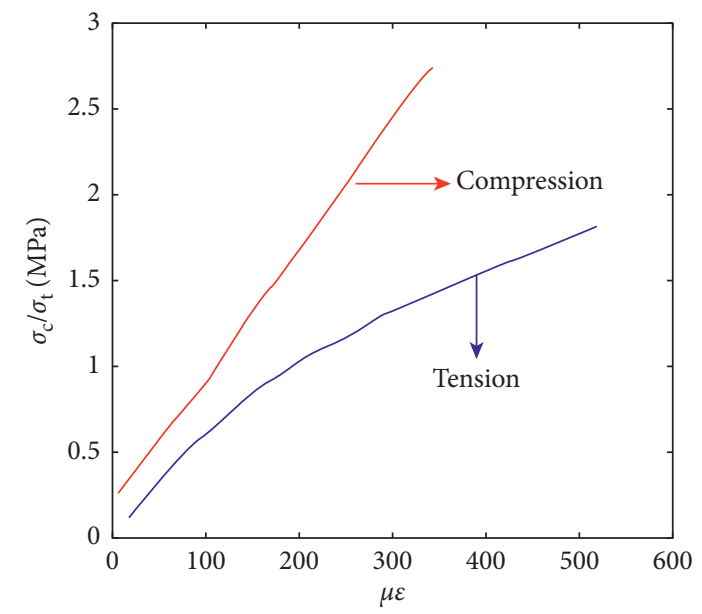

(d)

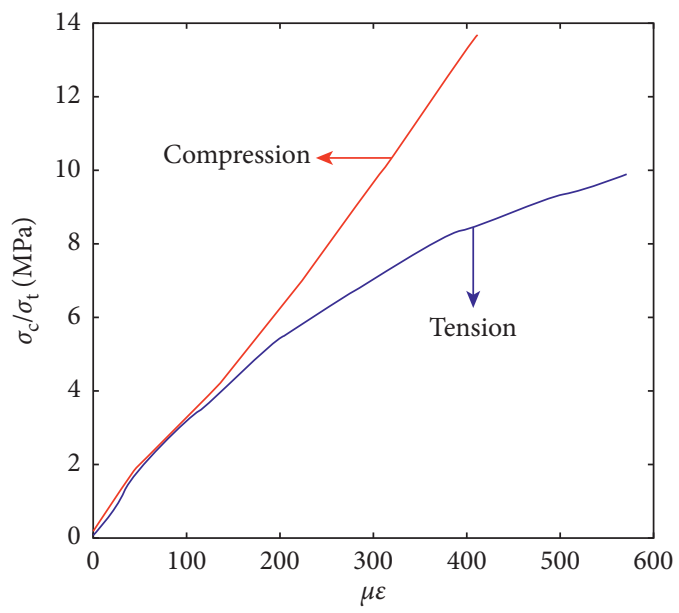

(f)

FIGURE 15: Typical stress-strain curves of marble, granite, and sandstone obtained from three-point bending test $\left(1 \mu \varepsilon=1.0 \times 10^{-6}\right)$. (a) MW1. (b) MW2. (c) MW4. (d) SW3. (e) GW1. (f) GW5.

Figure 15. The typical failure model of rock samples after three-points bending test is shown in Figure 16. It is observed that there is only a thick fracture in the middle part of sample beams, indicating that the failure of sample beam is due to tension at the bottom.

In Figure 15, the tensile strain is the average recorded by strain gauge 4, 5, and 6; while the compressive strain is recorded by strain gauge 1, as illustrated in Figure 5. The maximum compressive and tensile stress $\sigma_{\mathrm{c}}$ and $\sigma_{\mathrm{t}}$ at upper boundary and bottom of sample beam are determined according to Equations (1)-(3). It is clearly observed that tensile elastic modulus $E_{\mathrm{t}}$ is less than compressive elastic modulus $E_{\mathrm{c}}$ for all three types of rock. Parameters $E_{\mathrm{c}}, E_{\mathrm{t}}$, and tensile strength of rock samples from the three-point bending test are all listed in Table 6. Additionally, the tensile strength of rock samples measured by three-point bending test is also listed in Table 6.

3.4. Brazilian Disc Test Results. Typical tensile stress-strain curves at the center of disc for marble, granite, and sandstone obtained from Brazilian disc test are shown in Figure 17. Due to the fact that the sample preparation and test operation of Brazilian disc test are relatively simple, the success rate of Brazilian disc test is high in this study, and the testing results are also relatively stable. Typical failure model of rock samples after Brazilian disc test is shown in Figure 18. It is observed that the failure fractures basically go along the vertical diameter of disc, meeting the requirement of success for Brazilian disc test.

According to the theoretic formulation (equations (7)-(9)) proposed by Ye et al. [13], the tensile elastic modulus $E_{\mathrm{t}}$ of rock samples are determined and listed in Table 7. Meanwhile, the tensile strength from Brazilian disc test also is listed in Table 7. Poisson's ratios are all determined by the preceding UCT. From Table 7, it is known that the tensile elastic modulus of marble measured by Brazilian disc test is in the range of 5.1-7.9 GPa, averaging 6.2 GPa, that of granite is $12.4-14.7 \mathrm{GPa}$, averaging $13.5 \mathrm{GPa}$, and that of sandstone is $2.4-2.6 \mathrm{GPa}$, averaging $2.5 \mathrm{GPa}$. The tensile strength of marble, granite, and sandstone measured 


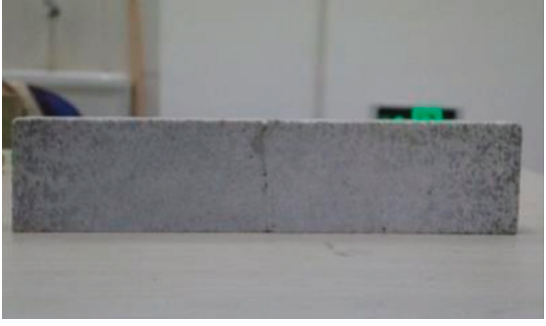

(a)

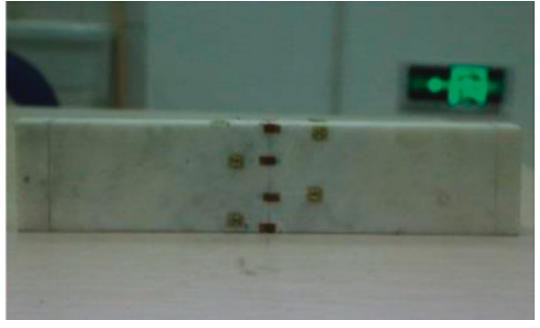

(b)

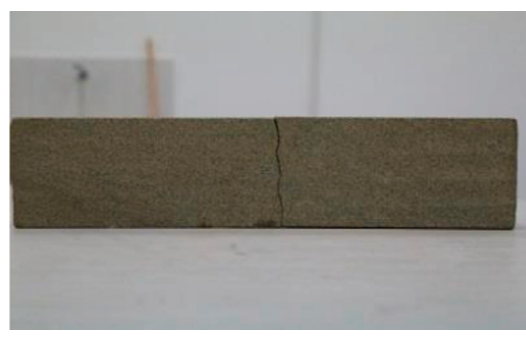

(c)

FIgURE 16: Typical failure model of rock samples after three-point bending test. (a) Granite. (b) Marble. (c) Sandstone.

TABLE 6: Test results of three-point bending test for marble, granite, and sandstone.

\begin{tabular}{lccc}
\hline Rock & $E_{\mathrm{c}}(\mathrm{GPa})$ & $E_{\mathrm{t}}(\mathrm{GPa})$ & Tensile strength $(\mathrm{MPa})$ \\
\hline MW1 & 11.70 & 8.00 & 3.8 \\
MW2 & 31.43 & 3.98 & 1.8 \\
MW4 & 17.47 & 10.38 & 3.0 \\
Mean & 20.20 & 7.45 & 2.87 \\
GW1 & 53.42 & 24.12 & 8.2 \\
GW5 & 31.16 & 26.27 & 10.0 \\
Mean & 42.29 & 25.20 & 9.1 \\
SW3 & 8.82 & 5.16 & 1.8 \\
\hline
\end{tabular}

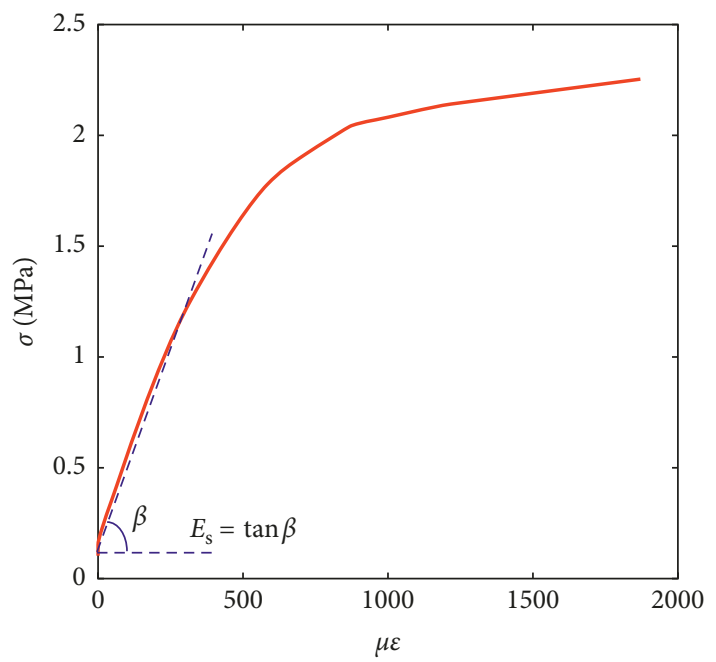

(a)

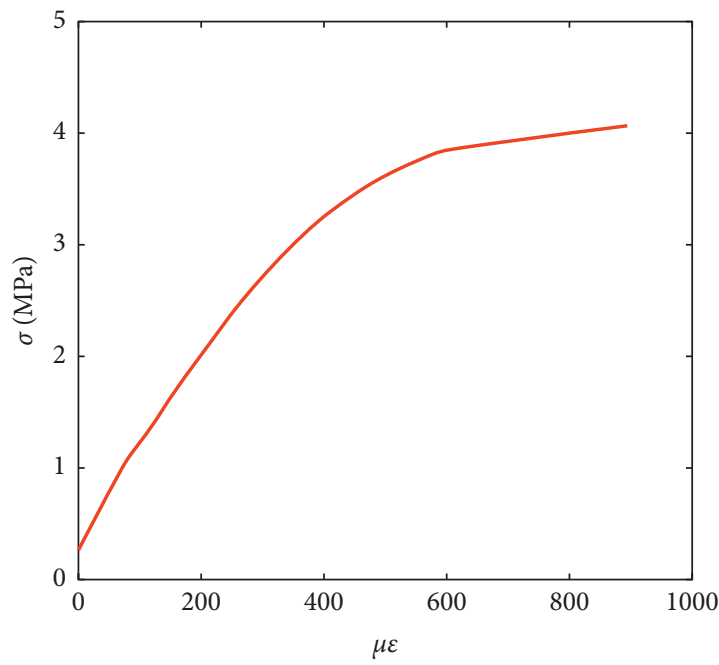

(c)

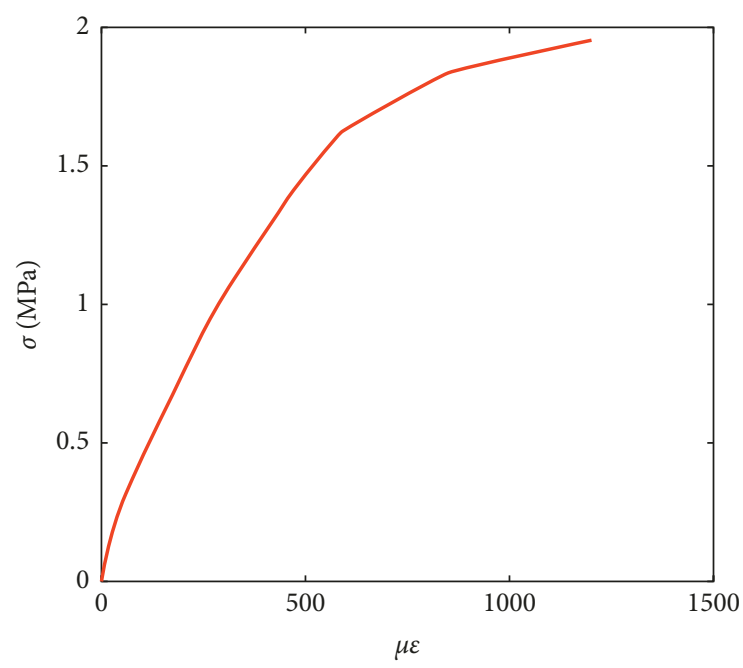

(b)

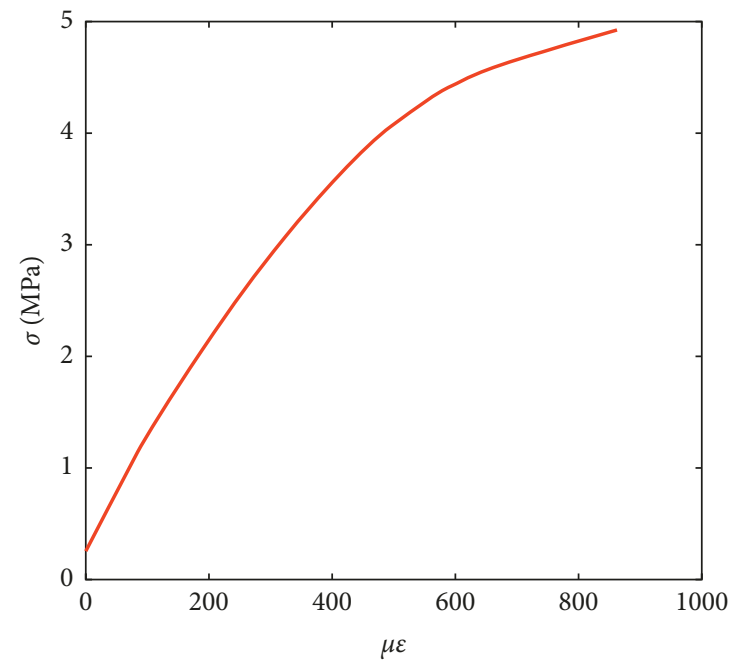

(d)

Figure 17: Continued. 


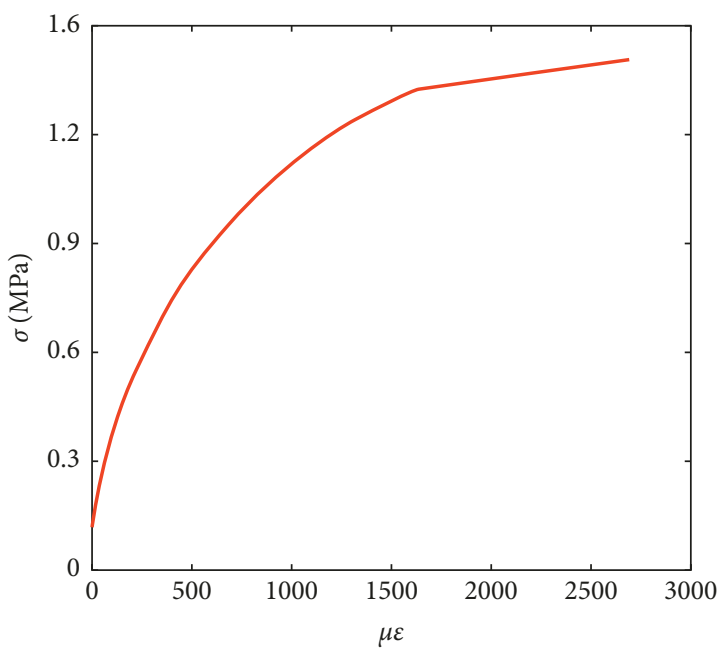

(e)

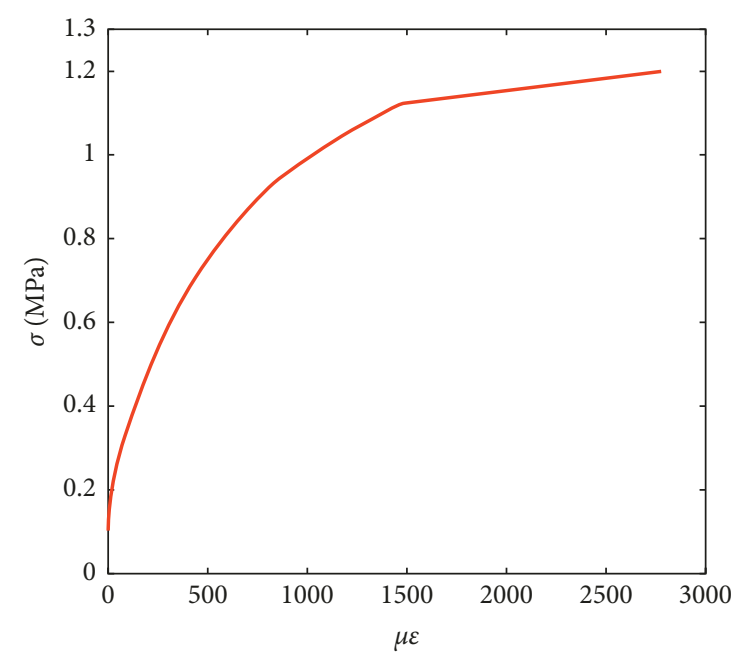

(f)

Figure 17: Typical tensile stress-strain curves at disc center of marble, granite, and sandstone obtained from Brazilian disc test $\left(1 \mu \varepsilon=1.0 \times 10^{-6}\right)$. (a) MP2. (b) MP5. (c) GP2. (d) GP4. (e) SP1. (f) SP4.

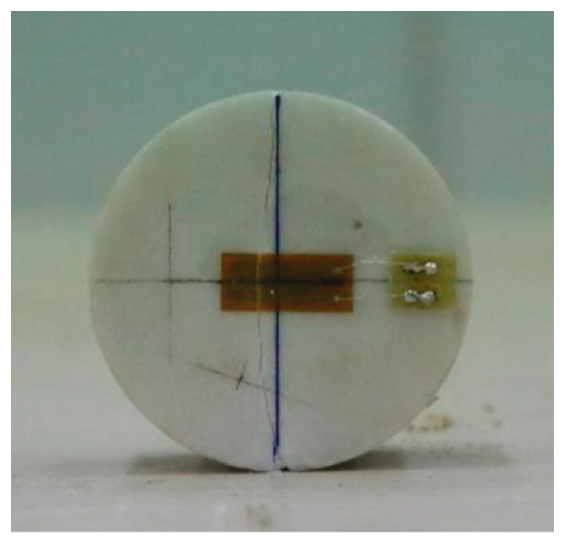

(a)

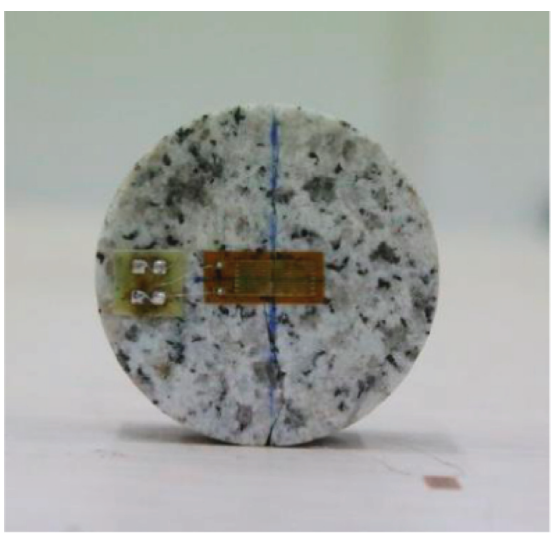

(b)

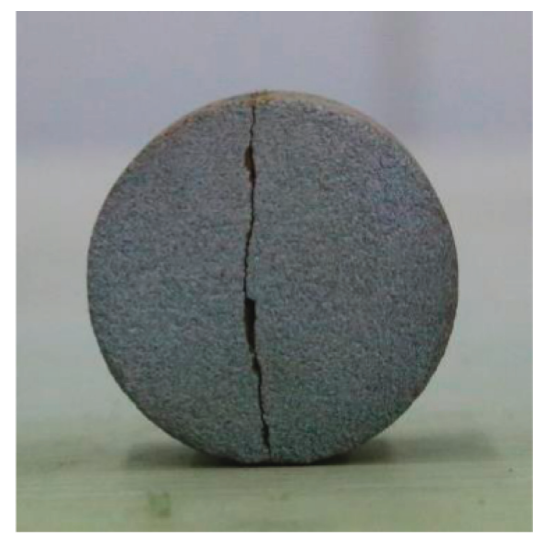

(c)

FIgURE 18: Typical failure model of rock samples after Brazilian disc test. (a) Marble. (b) Granite. (c) Sandstone.

by Brazilian disc test is averagely $2.05,4.40$, and $1.11 \mathrm{MPa}$, respectively.

3.5. Comparative Study. The basic purpose of this study is to screen which indirect test method, the three-point bending test or Brazilian disc test, is the better method to measure the tensile elastic modulus of rock materials. To implement this, all test results are summarized in Table 8 . In Table 8 , it is found that $E_{\mathrm{t}}$ and tensile strength measured by three-point bending test are much greater than that measured by DTT. The ratio is in the range of $170 \%$ to $203 \%$ for $E_{t}$, and it is $221 \%$ to $321 \%$ for tensile strength. While $E_{\mathrm{t}}$ and tensile strength of rock materials measured by Brazilian disc test are close to that measured by DTT. For granite and sandstone, the $E_{\mathrm{t}}$ measured by Brazilian disc test is slightly less than that measured by DTT, while it is much greater than that measured by DTT for marble. Due to the particularity of the marble used in this study, as stated in Section 3.2, this result of marble could not be representative. Therefore, we would prefer to make the following suggestions. (1) Tensile elastic modulus $E_{\mathrm{t}}$ of rock materials measured by the three-point bending test is much greater than its real value (here $E_{\mathrm{t}}$ measured by DTT is taken as the real value), and $E_{\mathrm{t}}$ measured by Brazilian disc test is slightly less than its real value, but it is more close to real value. (2) Tensile strength measured by indirect test method, regardless of three-points bending test or Brazilian disc test are both greater than that measured by DTT; however, the one measured by Brazilian disc test are more close to real value. (3) Due to the complexity of sample preparation and testing operation, the three-point bending test is not easy to be implemented. Additionally, due to the excellent test results, the Brazilian disc test can be suggested to be a suitable method to measure tensile elastic modulus of rock materials. 
TABLE 7: Test results of Brazilian disc test for marble, granite, and sandstone.

\begin{tabular}{|c|c|c|c|c|c|c|c|c|}
\hline Rock materials & SN & $E_{\mathrm{s}}(\mathrm{GPa})$ & $v$ & $D(\mathrm{~mm})$ & $L(\mathrm{~mm})$ & $A$ & $E_{\mathrm{t}}(\mathrm{GPa})$ & $\sigma_{\mathrm{t}}(\mathrm{MPa})$ \\
\hline \multirow{6}{*}{ Marble } & MP1 & 3.0 & \multirow{6}{*}{0.27} & 49.82 & \multirow{6}{*}{5} & \multirow{6}{*}{1.74} & 5.1 & 1.88 \\
\hline & MP2 & 3.6 & & 49.8 & & & 6.2 & 2.25 \\
\hline & MP3 & 4.6 & & 49.87 & & & 7.9 & 2.13 \\
\hline & MP4 & 3.5 & & 49.82 & & & 6.0 & 1.94 \\
\hline & MP5 & 3.3 & & 49.85 & & & 5.7 & 2.04 \\
\hline & Mean & 3.6 & & & & & 6.2 & 2.05 \\
\hline \multirow{6}{*}{ Granite } & GP1 & 9.8 & \multirow{6}{*}{0.19} & 49.73 & \multirow{6}{*}{5} & \multirow{6}{*}{1.49} & 14.7 & 4.46 \\
\hline & GP2 & 8.3 & & 49.72 & & & 12.4 & 4.07 \\
\hline & GP3 & 8.9 & & 49.76 & & & 13.3 & 4.14 \\
\hline & GP4 & 9.1 & & 49.86 & & & 13.6 & 4.92 \\
\hline & GP5 & - & & - & & & - & - \\
\hline & Mean & 9.0 & & & & & 13.5 & 4.40 \\
\hline \multirow{6}{*}{ Sandstone } & SP1 & 1.7 & \multirow{6}{*}{0.15} & 49.75 & \multirow{6}{*}{5} & \multirow{6}{*}{1.38} & 2.4 & 1.41 \\
\hline & SP2 & - & & 49.74 & & & - & 1.02 \\
\hline & SP3 & 1.8 & & 49.8 & & & 2.5 & 1.02 \\
\hline & SP4 & 1.9 & & 49.76 & & & 2.6 & 1.20 \\
\hline & SP5 & - & & 49.71 & & & - & 0.92 \\
\hline & Mean & 1.4 & & & & & 2.5 & 1.11 \\
\hline
\end{tabular}

Note. The test on GP5, SP2, and SP5 is not successful.

TABLE 8: Summarized test results of $E_{\mathfrak{c}}$, CS, $E_{\mathrm{t}}$, and TS determined by four types of test methods.

\begin{tabular}{|c|c|c|c|c|c|c|c|c|c|}
\hline Test type & & & & & Thr & point benc & test & Brazili & disc test \\
\hline Parameter & $E_{\mathrm{c}}(\mathrm{GPa})$ & $\mathrm{CS}(\mathrm{MPa})$ & $E_{\mathrm{t}}(\mathrm{GPa})$ & TS (MPa) & $E_{\mathrm{c}}(\mathrm{GPa})$ & $E_{\mathrm{t}}(\mathrm{GPa})$ & TS (MPa) & $E_{\mathrm{t}}(\mathrm{GPa})$ & TS (MPa) \\
\hline Marble & 63.6 & 107.6 & 3.7 & 1.3 & 20.2 & 7.5 & 2.87 & 6.2 & 2.05 \\
\hline Granite & 37.3 & 74.7 & 14.8 & 3.3 & 42.3 & 25.2 & 9.1 & 13.5 & 4.40 \\
\hline Sandstone & 3.4 & 22.4 & 3.0 & 0.56 & 8.8 & 5.2 & 1.8 & 2.5 & 1.11 \\
\hline
\end{tabular}

Note. CS, compression strength; TS, tension strength.

\section{Conclusion}

In this study, a series of experiment tests, including uniaxial compressive test (UCT), direct tensile test (DTT), threepoints bending test, and Brazilian disc test, are conducted for three typical types of rock materials: marble, granite, and sandstone. Compressive/tensile strength and elastic modulus $E_{\mathrm{c}}, E_{\mathrm{t}}$, and so on of rock materials are widely measured. Based on these measured results and comparative analysis, the following recognitions can be obtained. (1) The recorded strain value would be not representative if only one set of strain gauge is glued on rock samples. It is suggested that several sets of strain gauges are glued symmetrically on rock samples in UCT, DTT, and three-point bending test and that strain gauge should be glued, respectively, at the center of the two lateral sides of disc in the Brazilian disc test. (2) Due to the usage of the cementing material with high bonding strength (epoxy adhesive tube kit 2216B/A), performing the direct tensile test with cylinder samples is much easier than that if the shape of rock sample is dog bone. However, the success rate of DTT is still low. (3) Due to the complexity of sample preparation and testing operation, the success rate of three-point bending test is apparently low. It is only $40 \%$ in this study. (4) It is proposed that the Brazilian disc test could be a suitable method to measure the tensile elastic modulus of rock materials, due to the excellent agreement with the results measured by DTT and the simplicity of sample preparation, as well as testing operation.

\section{Data Availability}

The original data of stress-strain curves shown in Figures 12-18 used to support the findings of this study are available from the corresponding author upon request.

\section{Conflicts of Interest}

The authors declare that they have no conflicts of interest.

\section{Acknowledgments}

We appreciate the funding support from National Natural Science Foundation of China under project no. 41702308.

\section{References}

[1] H. Gercek, "Poisson's ratio values for rocks," International Journal of Rock Mechanics and Mining Sciences, vol. 44, no. 1, pp. 1-13, 2007.

[2] P. N. Sundaram and J. M. Corrales, "Brazilian tensile strength of rocks with different elastic properties in tension and compression," International Journal of Rock Mechanics and Mining Sciences \& Geomechanics Abstracts, vol. 17, no. 2, pp. 131-133, 1980.

[3] B. Lu, J. Wang, X. Ding, A. Wu, S. Duan, and S. Huang, "Study of deformation and cracking mechanism of surrounding rock of Jinping I underground powerhouse," Chinese Journal of 
Rock Mechanics and Engineering, vol. 29, no. 12, pp. 11981205, 2010.

[4] J. B. Wei, J. H. Deng, D. K. Wang, D. W. Cai, and J. Hu, "Characterization of deformation and fracture for rock mass in underground powerhouse of Jinping I hydropower station," Chinese Journal of Rock Mechanics and Engineering, vol. 29, no. 6, pp. 2429-2940, 2010.

[5] F. Wu, X. Hu, M. Gong, J. Liu, and A. Ren, "Unloading deformation during layered excavation for the underground powerhouse of Jinping I hydropower station, Southwest China," Bulletin of Engineering Geology and the Environment, vol. 69, no. 3, pp. 343-351, 2010.

[6] F. Wu, L. Tong, J. Liu, and X. Tang, "Excavation unloading destruction phenomena in rock dam foundations," Bulletin of Engineering Geology and the Environment, vol. 68, no. 2, pp. 257-262, 2010.

[7] W. Chiang and J. G. Yin, "A method for measuring both tensile and compressive elastic modulus of rock-like material," Rock and Soil Mechanics, vol. 19, pp. 93-96, 1998.

[8] C. Fairhurst, "On the validity of the "Brazilian" test for brittle materials," International Journal of Rock Mechanics and Mining Sciences \& Geomechanics Abstracts, vol. 1, no. 4, pp. 535-546, 1964.

[9] ISRM, "Suggested methods for determining tensile strength of rock materials," International Journal of Rock Mechanics and Mining Sciences \& Geomechanics Abstracts, vol. 15, no. 3, pp. 99-103, 1978.

[10] G. Hondros, "The evaluation of Poisson's ratio and the modulus of materials of a low tensile resistance by the Brazilian (indirect tensile) test with particular reference to concrete," Australian Journal of Applied Science, vol. 10, pp. 243-268, 1959.

[11] Y. Yu and T. X. Wang, "Study on relationship between splitting behavior and elastic modulus of three gorges granite," Chinese Journal of Rock Mechanics and Engineering, vol. 23, pp. 3258-3261, 2004.

[12] Q. Z. Wang, X. M. Jia, S. Q. Kou, Z. X. Zhang, and P.-A. Lindqvist, "The flattened Brazilian disc specimen used for testing elastic modulus, tensile strength and fracture toughness of brittle rocks: analytical and numerical results," International Journal of Rock Mechanics and Mining Sciences, vol. 41, no. 2, pp. 245-253, 2004.

[13] J. H. Ye, F. Q. Wu, and J. Z. Sun, "Estimation of the tensile elastic modulus of rock materials with Brazilian disc by applying opposite concentrate load diametrically based on isotropy," International Journal of Rock Mechanics and Mining Sciences, vol. 46, no. 3, pp. 568-576, 2009.

[14] D. Li and L. N. Y. Wong, "The Brazilian disc test for rock mechanics applications: review and new insights," Rock Mechanics and Rock Engineering, vol. 46, no. 2, pp. 269-287, 2013.

[15] F. Ming, D. Li, M. Zhang, and Y. Zhang, "A novel method for estimating the elastic modulus of frozen soil," Cold Regions Science and Technology, vol. 141, pp. 1-7, 2017.

[16] J. D. Tanks, D. K. Harris, and S. R. Sharp, "Mechanical response of unidirectional composite bars loaded in transverse compression," Composites Part B: Engineering, vol. 97, pp. 18-25, 2016.

[17] O. C. Gamboni, C. Riul, R. Billardon, W. W. Bose Filho, N. Schmitt, and R. B. Canto, "On the formation of defects induced by air trapping during cold pressing of PTFE powder," Polymer, vol. 82, pp. 75-86, 2016.

[18] N. Satyala, J. S. Krasinski, and D. Vashaee, "Simultaneous enhancement of mechanical and thermoelectric properties of polycrystalline magnesium silicide with conductive glass inclusion," Acta Materialia, vol. 74, pp. 141-150, 2014.

[19] B. Cicek, A. Tucci, E. Bernardo, J. Will, and A. R. Boccaccini, "Development of glass-ceramics from boron containing waste and meat bone ash combinations with addition of waste glass," Ceramics International, vol. 40, no. 4, pp. 6045-6051, 2014.

[20] J. H. Ye, F. Q. Wu, Y. Zhang, and H. G. Ji, "Estimation of the bi-modulus of materials through deformation measurement in a Brazilian disk test," International Journal of Rock Mechanics and Mining Sciences, vol. 52, no. 4, pp. 122-131, 2012.

[21] Y. Belrhiti, J. C. Dupre, O. Pop et al., "Combination of Brazilian test and digital image correlation for mechanical characterization of refractory materials," Journal of European Ceramic Society, vol. 37, no. 5, pp. 2285-2293, 2017.

[22] Y. Ju, Z. Ren, L. Wang, L. Mao, and F.-P. Chiang, "Photoelastic method to quantitatively visualise the evolution of whole-field stress in 3D printed models subject to continuous loading processes," Optics and Lasers in Engineering, vol. 100, pp. 248-258, 2018.

[23] G. W. Melenka and J. P. Carey, "Evaluation of fiber reinforced cement using digital image correlation," PLoS One, vol. 10, no. 6, Article ID e0128644, 2015.

[24] D. L. Zhu, L. Zhou, X. R. Zhang, and J. Y. Zhao, "Simultaneous determination of multiple mechanical parameters for a DNAN/ HMX melt-cast explosive by Brazilian disc test combined with digital image correlation method," Propellants, Explosives, Pyrotechnics, vol. 42, no. 8, pp. 864-872, 2016.

[25] S. Patel and C. D. Martin, "Application of digital image correlation technique for measurement of tensile elastic constants in Brazilian tests on a bi-modular crystalline rock," Geotechnical Testing Journal, vol. 41, no. 4, pp. 664-674, 2018.

[26] ASTM D3967-08, Standard Test Method for Splitting Tensile Strength of Intact Rock Core Specimens, ASTM International, West Conshohocken, PA, USA, 2008.

[27] GB/T 50266-2013, Standard for Test Methods of Engineering Rock Mass, China Planning Press, Beijing, China, 2013.

[28] ASTM D3148-02, Standard Test Method for Elastic Moduli of Intact Rock Core Specimens in Uniaxial Compression, ASTM International, West Conshohocken, PA, USA, 2002.

[29] ISRM, "Suggested method for the complete stress-strain curve for intact rock in uniaxial compression," International Journal of Rock Mechanics and Mining Sciences \& Geomechanics Abstracts, vol. 36, no. 3, pp. 281-289, 1999. 


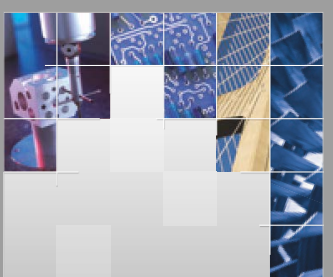

\section{Enfincering}
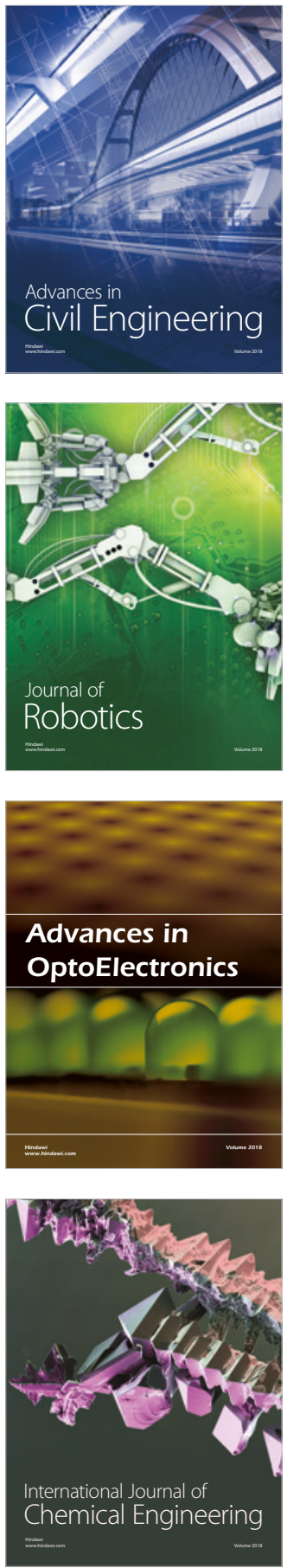

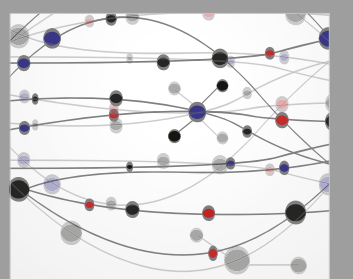

\section{Rotating \\ Machinery}

The Scientific World Journal

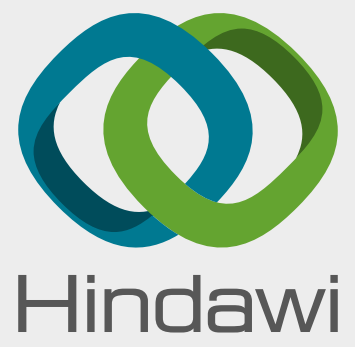

Submit your manuscripts at

www.hindawi.com
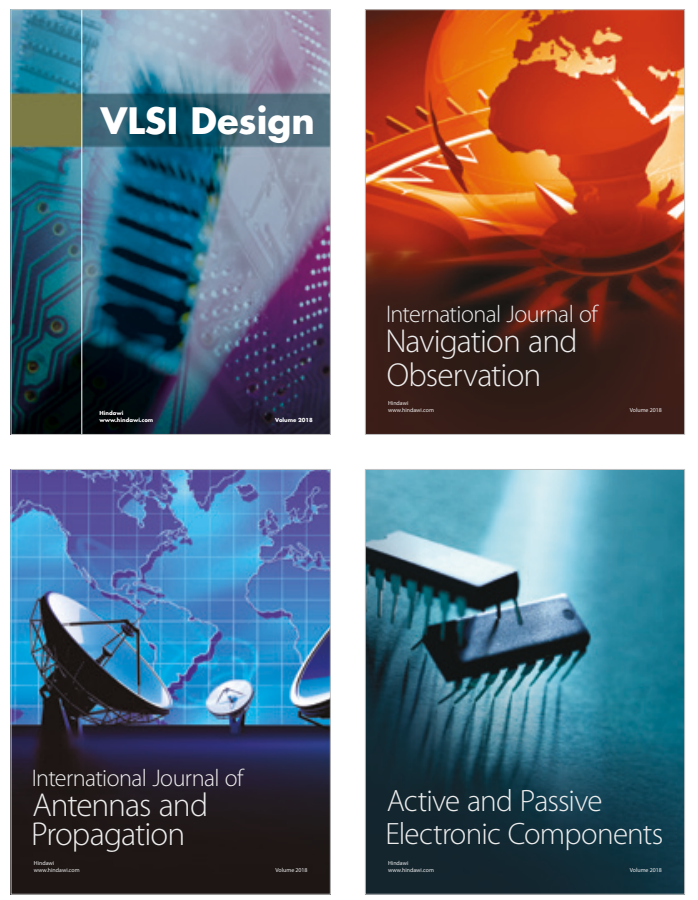
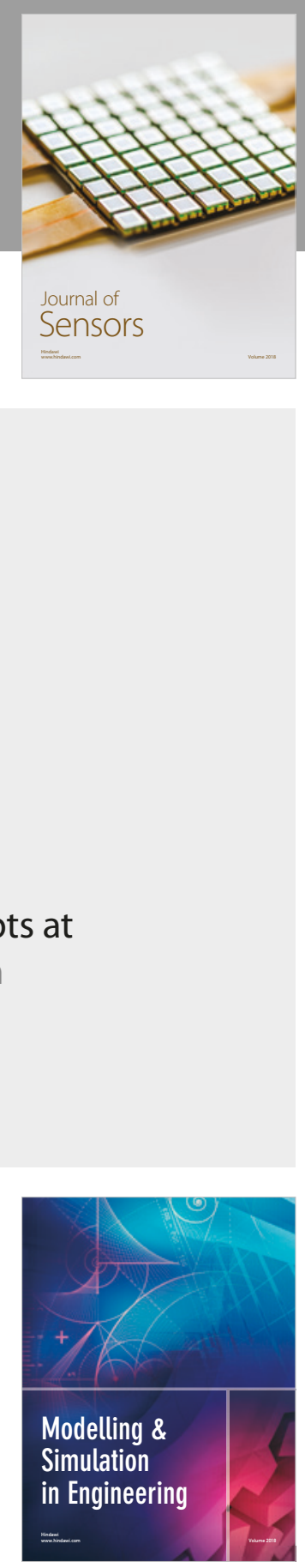

\section{Advances \\ Multimedia}
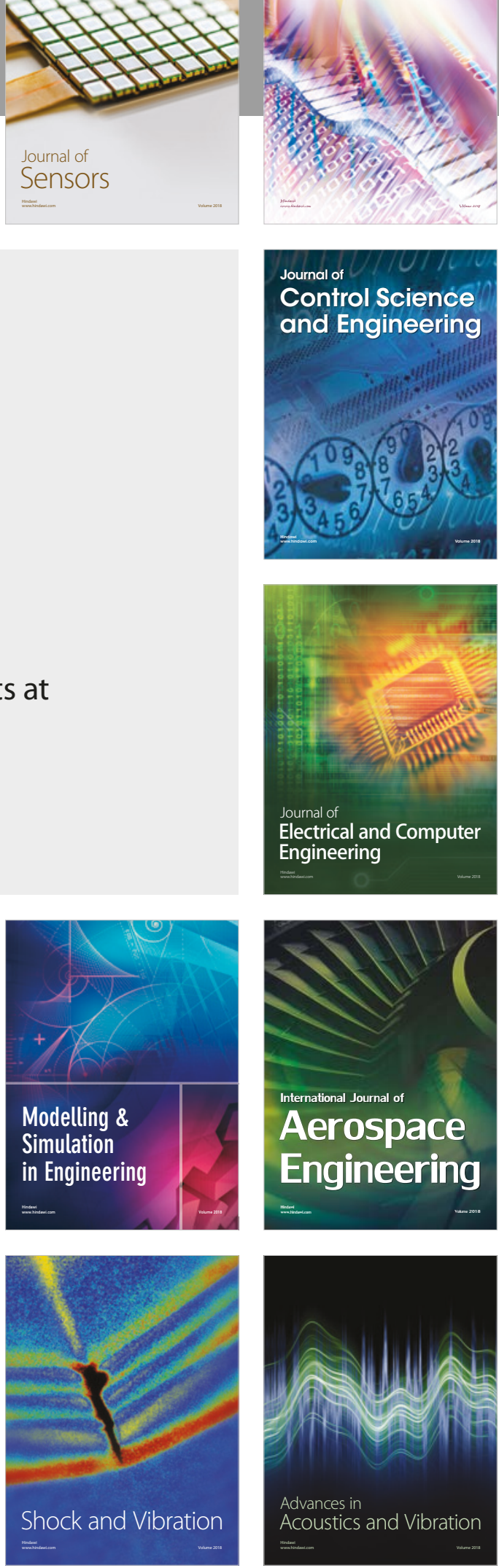